\title{
A Theoretical Investigation of Hybrid Foil-Magnetic Bearings on Operation Mode and Load Sharing Strategy
}

\author{
Kai Feng ( $\nabla$ jkai.feng@gmail.com ) \\ Hang Zhang \\ Hunan University \\ Qianwei Yin \\ Hunan University \\ Hanqing Guan \\ Hunan Institute of Engineering \\ Yuanlong Cao \\ University of South China
}

Hunan University https://orcid.org/0000-0002-9287-9379

\section{Original Article}

Keywords: Hybrid foil-magnetic bearing, Operation mode, Load sharing strategy, Prediction model, Static and dynamic performance

Posted Date: September 22nd, 2020

DOl: https://doi.org/10.21203/rs.3.rs-78145/v1

License: (9) (1) This work is licensed under a Creative Commons Attribution 4.0 International License. Read Full License 


\title{
A theoretical investigation of hybrid foil-magnetic bearings on operation mode and load sharing strategy
}

\author{
Kai Feng ${ }^{1}$, Hang Zhang ${ }^{1}$, Qianwei Yin ${ }^{1}$, Hanqing Guan ${ }^{2}$, Yuanlong Cao ${ }^{3}$
}

\begin{abstract}
To guide the conceptual design of hybrid foil-magnetic bearings (HFMBs), this paper presents a theoretical investigation on operation mode and load sharing strategy. According to the inherent characteristics of GFBs and AMBs, seven possible work scopes are discussed to understand the operation mode of HFMBs. A numerical model coupling the calculations of the film pressure in GFBs and the magnetic forces in AMBs is conducted to predict the performance of HFMBs. The deflection of top foil and bumps is also included in the prediction model. The analysis, which is conducted for static and dynamic performance of HFMBs within three representative work scopes by varying the load sharing, uncovers the effects of the operation mode and load sharing strategy on bearing behavior. Results show that HFMBs performance including the supporting stiffness and stability can be obviously enhanced by adjusting the operating mode and load sharing strategy.
\end{abstract}

Keywords: Hybrid foil-magnetic bearing, Operation mode, Load sharing strategy, Prediction model, Static and dynamic performance

\section{INTRODUCTION}

Advanced energy and power equipment with high operating speeds, high 
energy density, and high working efficiency require oil-free bearings to have more comprehensive performance and adaptability to severe environment. Gas foil bearings (GFBs) and active magnetic bearings (AMBs), as two innovative types of oil-free bearings, are able to meet the requirements of most high-speed machines and have been developed and investigated for several generations [1].

GFBs, as a type of compliant, self-acting hydrodynamic fluid film bearings using ambient gas as lubricant, have shown many advantages including inherent simple structure, no complex oil lubrication and sealing system, excellent high-speed operation characteristics and tolerance for high temperatures [2]. To date, GFBs have been successfully used in many oil-free machinery applications, such as air cycle machine in aircrafts [3], turbochargers [4, 5], turbojet engine [6, 7], and micro gas turbine engine [8-10]. However, there are still some issues that hinder the development of GFBs. A special friction-resistant coating are needed on the surface of top foil to extend the applicable bearing life [11]. Due to its poor damping property, extra coulomb damping is usually required to increase the high-speed stability of GFBs during the design of the compliant structure [12].

AMBs generate forces through magnetic fields. There is no contact between bearing and rotor, which permits operation with no lubrication and no mechanical wear [13]. Current industrial applications of AMBs 
include vacuum and cleanroom systems [14, 15], machine tools [16], medical devices [17, 18], turbo-machinery $[19,20]$. However, in high-speed applications, AMBs are easily affected by structural resonance, which is the primary reason leading to the control system instability [1]. Moreover, the lack of reliable and durable auxiliary bearing is also an issue that should be solved when AMBs are operated under high speeds [21].

Hybrid foil magnetic bearings (HFMBs), as shown in Fig. 1, combine the above two oil-free bearing technologies. The unique coupling method enables HFMBs to make full use of the advantages of both bearings while effectively overcoming the disadvantages. However, as the two bearings are mutually dependent and influenced, to make them operate in a coordinated manner become extremely important for the design of HFMBs. That is to say the adjustment of the rotor by AMBs must be consistent with the working condition of GFBs.

Heshmat et al. [1, 22] presented an experimental investigation on HFMBs and proposed the earliest control algorithms for the load assignment of on the two bearings, GFBs and AMBs. Swanson et al. [23] designed a test rig supported by a HFMB system to simulate the rotor dynamics of a small gas turbine engine. Jeong et al. [24] built an experiment set-up to analyze the performance of rigid rotor supported by combined smart bearings on critical speeds with PD control. Tian et al. [25] presented a 
searching algorithm to determine the steady-state working position of a hybrid foil-magnetic bearing. Pham and Ahn [26] conducted an experimental investigation on the parameter optimization of hybrid foilmagnetic bearings to support a flexible rotor. Yang et al [27] presented a theoretical method to calculate the load capacity, dynamic stiffness and damping coefficients of HFMBs under a specified load sharing factor $\lambda$ with the predetermined operational state. Jeong and Lee [28] tested a rigid rotor supported by HFMBs to elucidate the effect of initial eccentric position on the vibration response of rotor. Jeong et al. [29] developed a $225 \mathrm{~kW}$ class turbo blower by including hybrid foil-magnetic bearings. Tian and Sun [30] presented an adaptive control method to simplify the controller design and improve the performance of the rotor-HFMB system. Jeong and Lee [31] used a control algorithm to reduce the sudden imbalance vibration amplitudes of a rigid rotor which was operated at up to $12,000 \mathrm{rpm}$. Basumatary et al. [32] presented a dynamic model that coupled dynamics of gas foil bearings and electromagnetic actuator to discusses the effect of electromagnetics actuators on the stability of a rotor supported on gas foil bearings.

However, HFMBs design remains largely empirical, in spite of a small amount of successful applications. Obviously, in the actual application of HFMBs, GFBs and AMBs will play different roles when the equipment is operated at different conditions. A sloppy design by just simply coupling 
the two kinds of bearings will not be sufficient to extract the full performance potential of HFMBs and lead to oversize bearing. GFBs and AMBs, based on different working principles, have their own unique and distinct characteristics. Thus, distributing the work of the two bearings reasonably according the system requirement can be definitely complex. Although rotor systems supported by HFMBs were investigated for oil-free turbo-machineries and some empirical hybrid arrangements for HFMBs were obtained, there are few theoretical analyses to explore the optimal performance of HFMBs including active and passive components matching strategy.

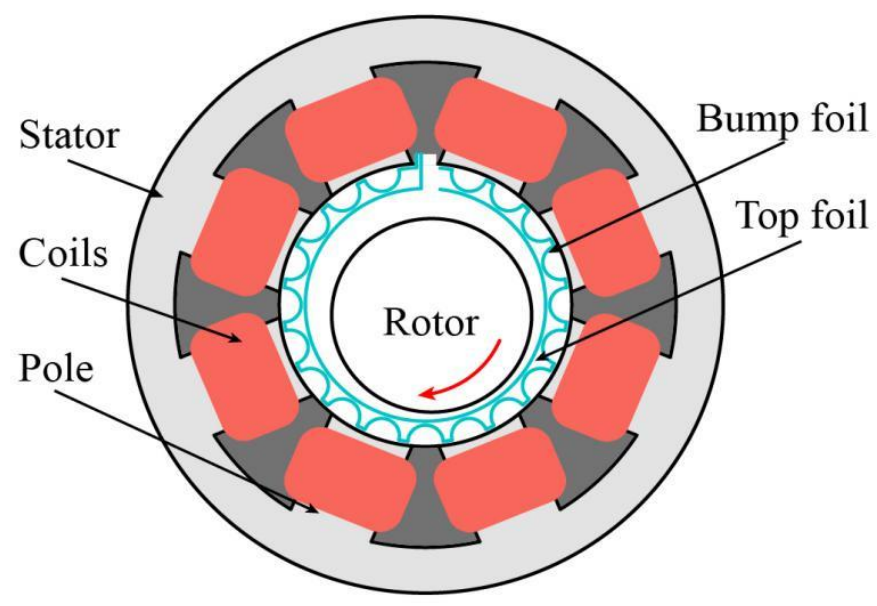

Fig. 1. The structure of hybrid foil magnetic bearings

Based on the characteristics of GFBs and AMBs, the possible work scope of HFMBs with respect to load capacity and rotational speed is discussed. A numerical model coupling the calculations of the film pressure in GFBs and the magnetic forces in AMBs is conducted to calculate the static and dynamic performance of HFMBs. Prediction results of the bearing 
performance under different operating conditions were given and the importance of matching design between GFBs and AMBs was illustrated. This work is to be used as a preliminary design study to develop turbomachinery supported by HFMBs.

\section{Characteristics of Hybrid Foil-Magnetic Bearings}

HFMBs are configured as a nested design by inserting GFBs components in the radial gap between the AMB poles and the rotor, as shown in Fig. 2. AMBs directly act on the rotor by magnetic force, while GFBs support the rotor through hydrodynamic pressure in the gas film. The performance of HFMBs is the result of the joint action of the two bearings.

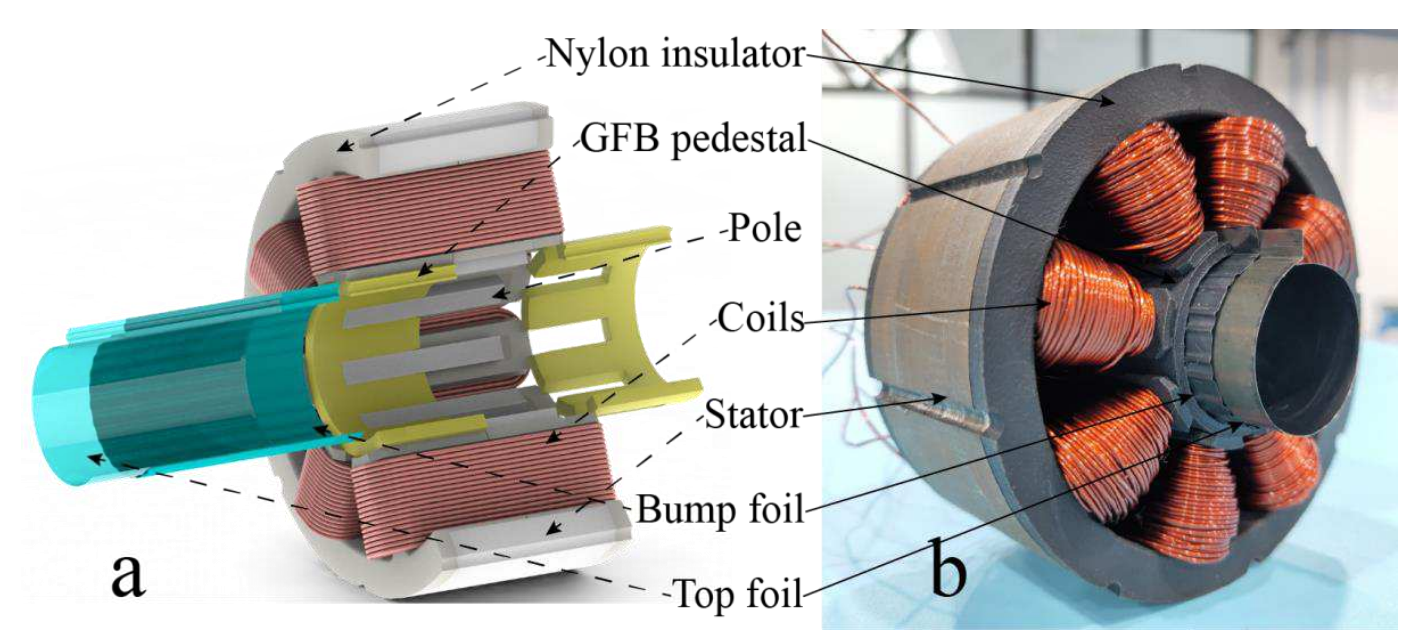

Fig. 2. Schematic diagram of HFMBs (a) and photograph of a test bearing (b)

\subsection{Operation range of GFBs and AMBs}

The structure of GFBs consist of a smooth top foil and a flexible corrugate bump foil, as shown in Fig. 2a. GFBs have no physical 
clearance between the top foil and rotor at rest. When the rotor rotates, the high gas pressure will be generated and cause the foils to provide elastic deflection and frictional damping. The main factors limiting the work scope of GFBs are load capacity and bearing stability, as shown in Fig. 3a. The bearing load capacity increases with the rise of the rotational speed until it reaches a certain value [33]. Meanwhile, GFBs will become unstable as the increase speed due to the sub-synchronous vibration (cross-coupled stiffness) [34-36]. The suitable work scope of GFBs is shown in Fig. 3a. Generating contact free magnetic field forces by actively controlling the dynamics of an magnetic is the principle of AMBs which is actually used most often among the magnetic suspensions [37]. Stiffness, damping, as well as load capacity, can be varied widely within physical limits, and can be adjusted to technical requirements. The dynamics of the contact-free hovering depends mainly on the implemented control law [38-43]. The suitable work scope of AMBs is shown in Fig. 3b.
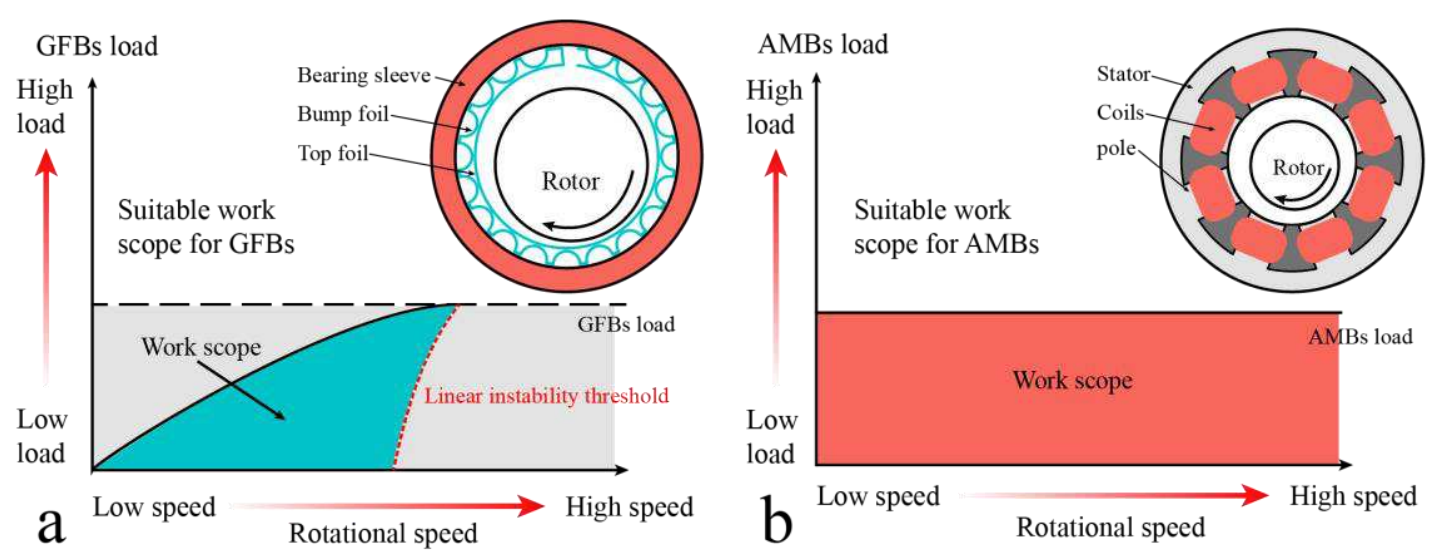

Fig. 3. Suitable work scope of gas foil bearings (a) and active magnetic bearings 


\subsection{Operation range of HFMBs}

In Fig. 4, the work scope of HFMBs is divided into seven parts on the basis of the relationship between load capacity and speed of the two bearings. The specific load capacity of the bearing depends on the type of ferromagnetic material and the design of the bearing magnet. It will be about $20 \mathrm{~N} / \mathrm{cm}^{2}$ and can be as high as $40 \mathrm{~N} / \mathrm{cm}^{2}$ [37]. The designed load capacity of AMBs is usually less than that of GFBs in a hybrid system in view of larger air gap and more compact structure. The function of seven work scopes is described briefly below.

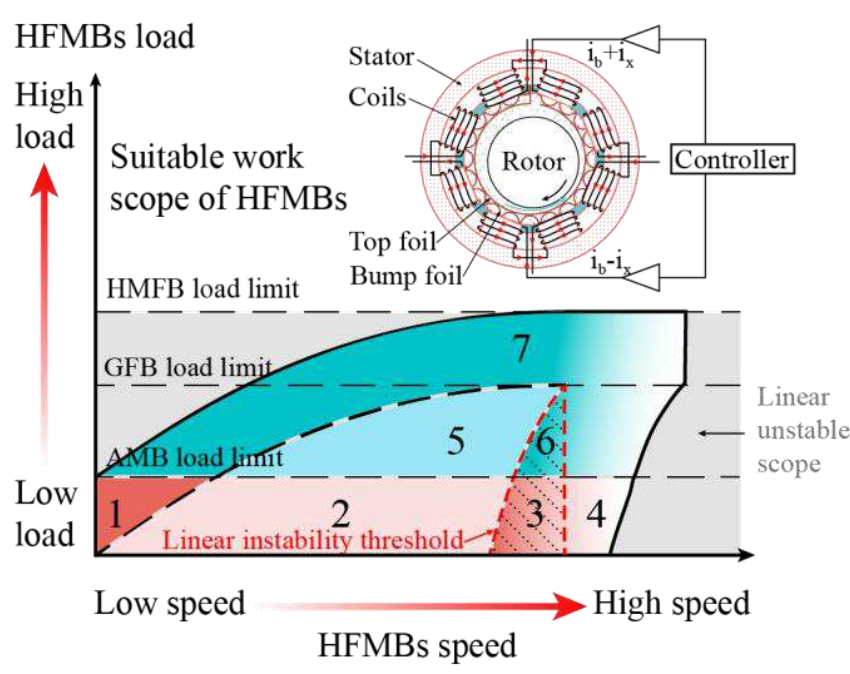

Fig. 4. Work scope of hybrid foil magnetic bearings

Scope 1: As the rotational speed is low, the gas pressure generated between the top foil and the rotor is not enough to support the bearing load. Therefore, it is suggested to use AMBs in this scope (no need to use HFMBs).

Scope 2: As the increase of rotational speed, the rotor may be separately 
loaded by GFBs or AMBs. Different operation modes represent different load ways. That means in this scope HFMBs can suspend rotor by AMBs or GFBs individually, or the hybrid way.

Scope 3, 4: With the further increase of rotational speed, GFBs supporting system will show linear instability. However, due to the addition of the active control system (AMBs), the dynamic performance of the bearing is enhanced, and the linear stable scope expands towards the high-speed direction. Note that the difference between scope 3 and scope 4 is that the electromagnetic forces from AMBs which are used to stabilize GFBs are applied along different directions.

Scope 5: The load exceeds the load capacity of AMBs, thus the rotor can be supported by GFBs alone or HFMBs.

Scope 6: As the rotational speed increases, GFBs steps into its linear unstable range and have the possibility of instability. By applying electromagnetic force to increase the bearing eccentricity, GFBs can be stabilized again. GFBs and AMBs are unable to support the rotor alone in scope 6.

Scope 7: The bearing load exceeds both the load capacity of GFBs or AMBs. Thus, the only choice for the system is to use HFMBs to support the rotor. 


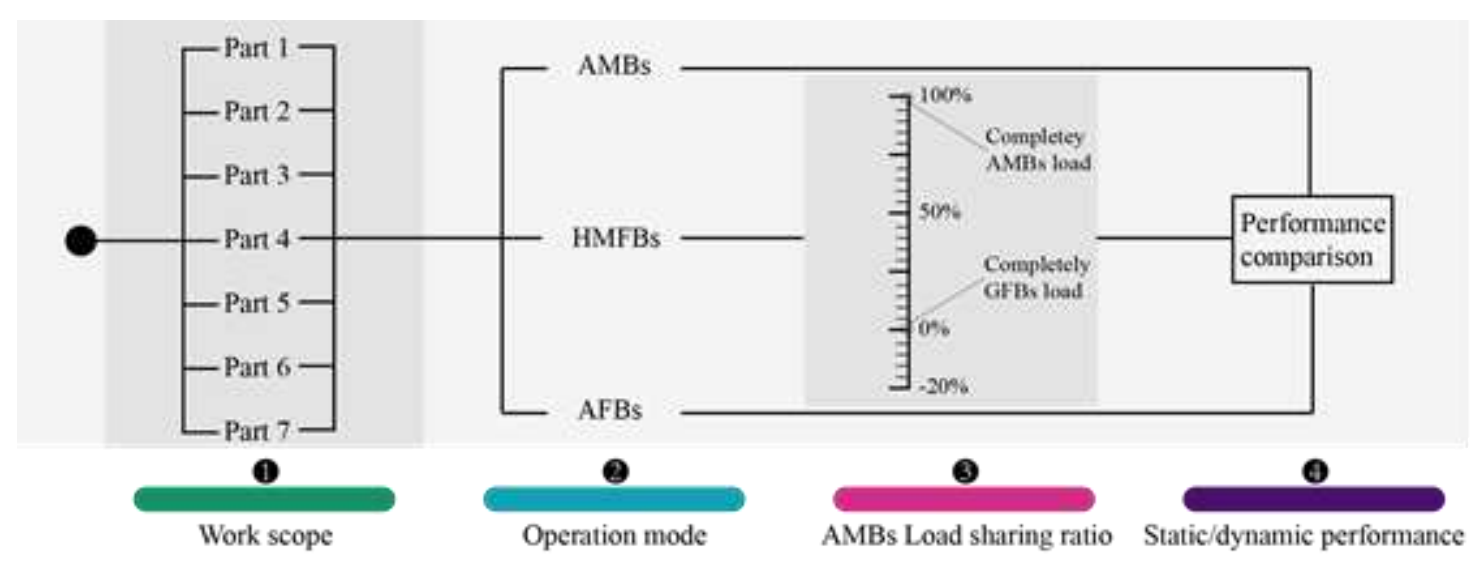

Fig. 5. Specific operation mode of the HFMBs load sharing strategy

Fig. 5 explains the effect of operation mode and load sharing strategy on the HFMBs performances. A determined working state correspond to a certain part of HFMBs work scope which may adopt one or more of the three different operation modes (GFBs individually, AMBs individually and hybrid bearings). The static and dynamic performance of the HFMBs can be affected by adjusting the load sharing ratio, even applying magnetic force to increase the rotor mass when adopting hybrid operation mode. The ultimate objective is acquiring the effect of operation modes and sharing ratio on static and dynamic performance adopting the numerical calculation at different parts of HFMBs work scope.

\section{Theoretical model of hybrid foil-magnetic bearings}

\subsection{Gas foil bearing model}




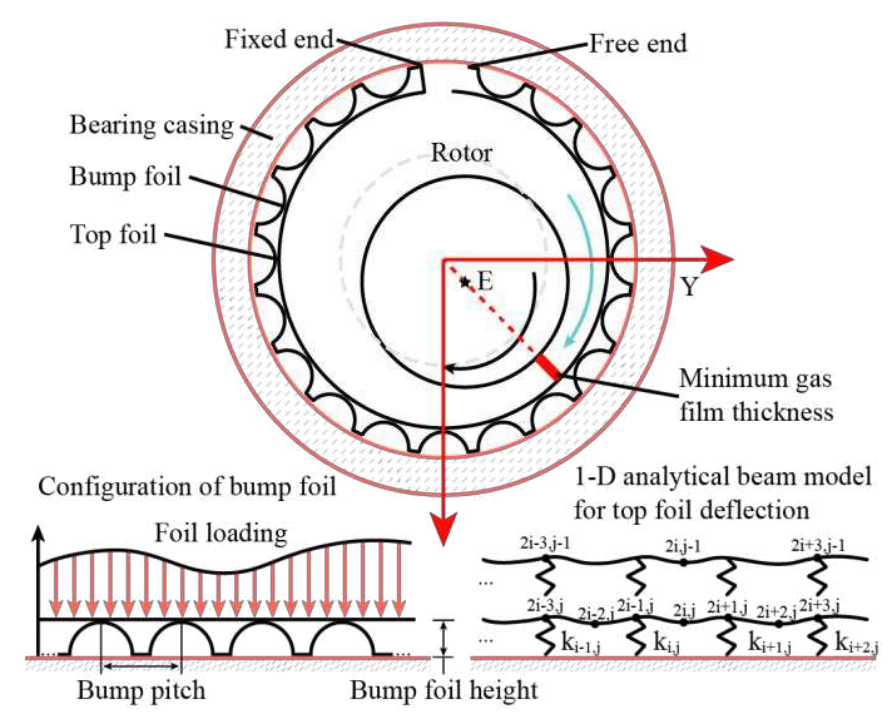

Fig. 6. Calculation model of gas foil bearings

Fig. 6 schematically presents the fundamental configuration and nomenclature for self-acting hydrodynamic GFBs. In GFBs, the top and bump foils act as supporting elements for the air film. The air and the supporting foil structure operate in series. $i$ and $j$ respectively represent the number of bumps and number of the calculated nodes in the axis direction.

Based on the continuity equation, Navier-Stokes equation and gas state equation, the prediction of the air pressure distribution between rotor and top foil can be solved by the dimensionless Reynolds equation using finite difference method [44]:

$\frac{\partial}{\partial \theta}\left(\bar{p} \bar{h}^{3} \frac{\partial \bar{p}}{\partial \theta}\right)+\frac{\partial}{\partial \bar{z}}\left(\bar{p} \bar{h}^{3} \frac{\partial \bar{p}}{\partial \bar{z}}\right)=\Lambda \frac{\partial(\bar{p} \bar{h})}{\partial \theta}+2 \Lambda \gamma \frac{\partial(\bar{p} \bar{h})}{\partial \bar{t}}$

In the static calculation process of GFBs, the specific bearing load and speed correspond to a certain eccentricity and attitude angle of the rotor under the action of gas film force. In the dimensionless process of 
Reynolds equation of compressible gas, the following dimensionless parameters are considered:

$\bar{p}=\frac{p}{p_{a}}, \bar{h}=\frac{h}{C}, \bar{z}=(z / R), \Lambda=\frac{6 \mu \Omega}{p_{a}}\left(\frac{R}{C}\right)^{2}$

Referring to Eq. (1), it should be noted that the gas film thickness depends not only on the initial eccentricity and attitude angle, but also on the elastic deformation of the supporting structure. Therefore, the gas film thickness equation can be obtained:

$h=C+e \cdot \cos \left(\theta-\theta_{0}\right)+[\delta]$

$\delta$ is the compliant surface deformation. It can be seen from Fig. 6 that zero slopes at both ends are an appropriate approximation because the top foil is continuous and the slope at each bump support is close to zero. The deflection of the top foil at the center between two adjacent bumps can be found as [45]:

$v_{2 i, j}=\frac{s^{4} \Delta z}{1920 E I}\left(3 p_{2 i+1, j}+3 p_{2 i-1, j}-p_{2 i, j}\right)$

Where, EI is the bending stiffness of the top foil segment. Note that the local deflection function above was found assuming each bump is rigid, hence the total top foil deflection along the radial direction can be calculated by adding the local deflection of top foil to the bump deflection. The bumps are considered as springs with a constant structural stiffness, so the normalized foil deformation is given by [46]: 


$$
\left\{\begin{array}{l}
\delta_{2 i-1, j}=\frac{2 S}{E}\left(\frac{l_{0}}{t}\right)^{3}\left(1-v^{3}\right)(p-p a) \\
\delta_{2 i, j}=\frac{2 s}{E}\left(\frac{l_{0}}{t}\right)^{3}\left(1-v^{3}\right)(p-p a)+\frac{s^{4} \Delta z}{1920 E I}\left(3 p_{2 i+1, j}+3 p_{2 i-1, j}-p_{2 i, j}\right)
\end{array}\right.
$$

The solution of Reynolds equation must be based on the deflection of foil structure and the distribution of gas film pressure. At both ends of GFBs along the axial direction, the gas film boundary is connected with the atmosphere, which can be regarded as the same as the atmospheric pressure. The gas film at the starting point and the ending point is also connected with the atmosphere. The boundary condition of Eq. (1) is:

$$
\left\{\begin{array}{l}
p=p a, z= \pm L / 2 \\
p=p a, \theta=0,2 \pi
\end{array}\right.
$$

(6)

\subsection{Active magnetic bearing model}

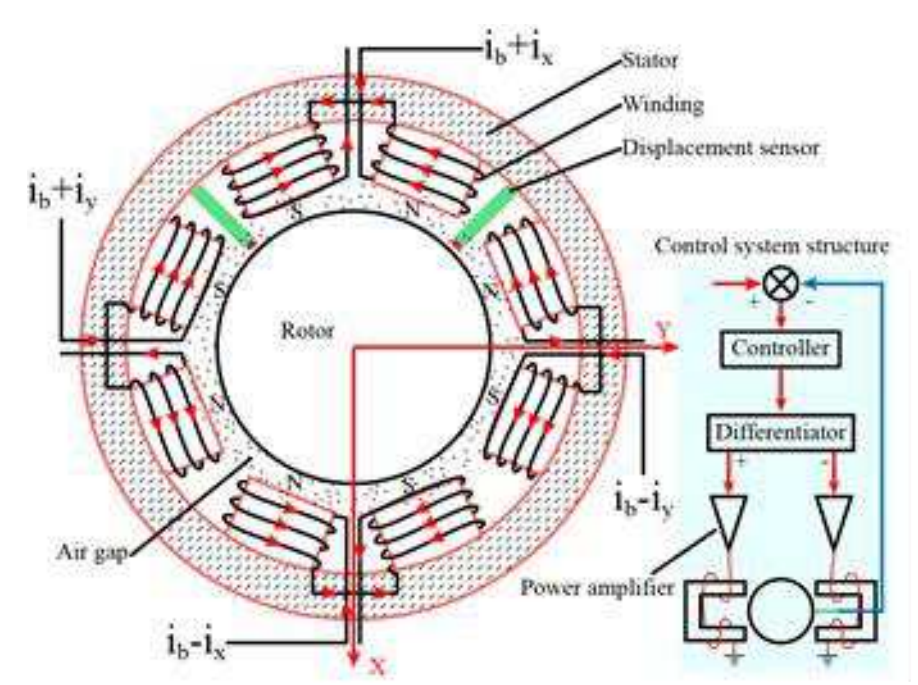

Fig. 7. Schematic diagram of active magnetic bearing

Fig. 7 depicts a simple example of a magnetic bearing control loop though comprising all the necessary components of a "standard" active 
magnetic bearing system. A magnetic bearing system can usually be well controlled by a liner control scheme despite these strong nonlinearities. The force/displacement and the force/current dependencies of the magnet force $F_{x}$ have to be linearized at operating point $\left(x_{0 x}, i_{0 x}, m g\right)$ which denotes the desired equilibrium position [37]:

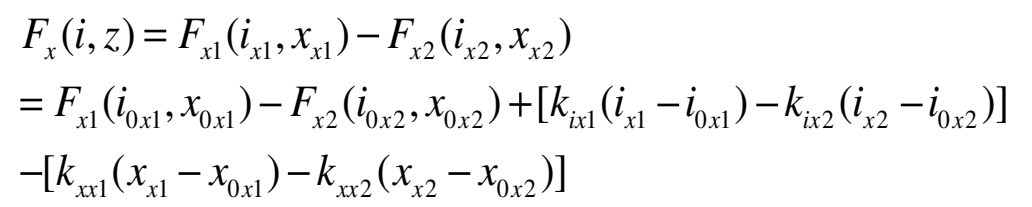

The constant $k_{i x}(\mathrm{~N} / \mathrm{A})$ and $k_{x x}(\mathrm{~N} / \mathrm{m})$ in Eq. (7) are commonly called by the force/current factor and force/displacement factor. However, it is a bit different between HFMBs and AMBs. The equilibrium position may alter when the rotor speed or load are varied and the generated equilibrium displacement $x_{x 1}, x_{x 2}$ and current $i_{x 1}, i_{x 2}$ can be described as:

$$
\left\{\begin{array}{l}
x_{x 1}=x_{01}-\Delta x \\
x_{x 2}=x_{02}+\Delta x \\
i_{x 1}=i_{x 0}-\Delta i \\
i_{x 2}=i_{x 0}+\Delta i
\end{array}\right.
$$

The magnetic force along $X$ direction of HFMBs can be written simplistically:

$$
F_{x}(i, z)=F_{x 1}\left(i_{x 1}, x_{x 1}\right)-F_{x 2}\left(i_{x 2}, x_{x 2}\right)=C_{c u r}-\left(k_{i x 1}+k_{i x 2}\right) \Delta i+\left(k_{x x 1}+k_{x x 2}\right) \Delta x
$$

The first part of Eq. (9) represents a constant value determined by bias current after confirming the static equilibrium position of the rotor. The 
equilibrium position of the electromagnetic system causes the changes of force/current factor and force/displacement factor of the two groups of magnets as well as the electromagnetic force at the static equilibrium position. Different Taylor series at different equilibrium positions lead to different linearized mathematical models of electromagnetic force.

\subsection{Hybrid foil magnetic bearing model}

The schematic diagram of HFMBs system is shown in Fig. 8. The load of an off-centre operation HFMBs is divided into two parts. One is borne by the hydrodynamic pressure between the top foil and the rotor, while the other is borne by the magntic force generated by a pair of poles along the $\mathrm{X}$-axis direction. In addition, AMBs control current plays a role in providing dynamic stiffness and damping and suppressing rotor vibration.

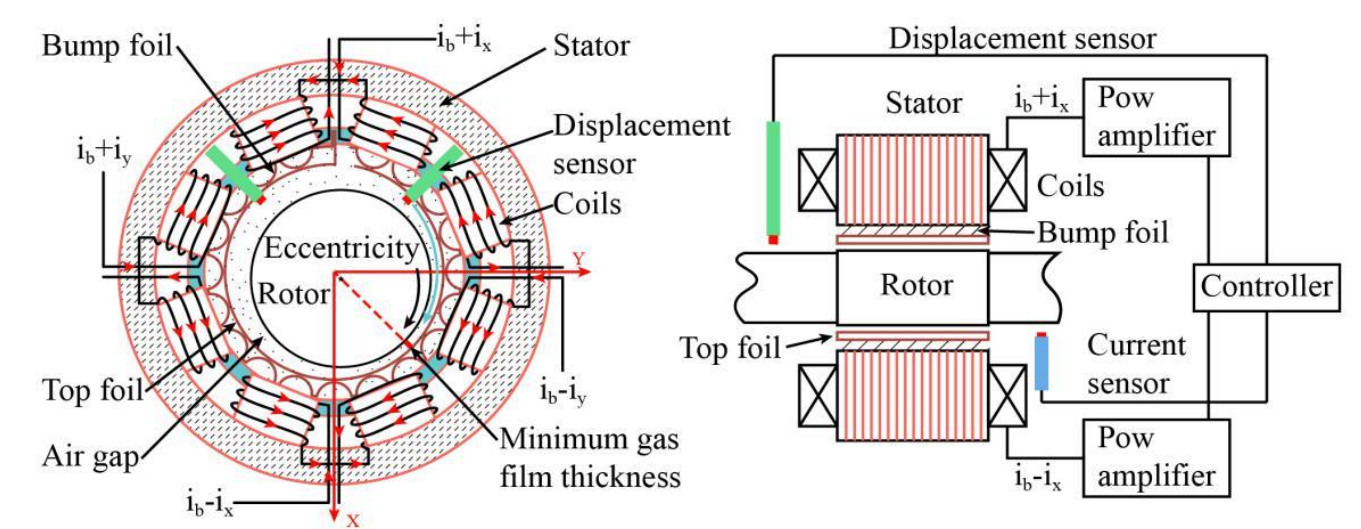

Fig. 8. System structure schematic diagram of hybrid foil magnetic bearings

In order to ensure that GFBs and AMBs do not interfere with each other, the rotor center of GFBs under specified load must be calculated first. According to the rotor center, the bias current that need to be provided by AMBs is calculated. In order to study the effect of load sharing strategy 
on the performance of HFMBs, it is assumed that the PID controller gains will not change with the working state.

The calculation process of static and dynamic performance of HFMBs is shown in Fig. 9. According to the load assigned to GFBs, the finite difference method is used to solve the static Reynolds equation with consideration of the elastic deflection of the foil structure. The small perturbation method is used to predict the dynamic coefficients of GFBs. On the basis of the static results of GFBs and the bias current of AMBs according to the rotor center, the dynamic stiffness and damping coefficients of AMBs can be calculated. The dynamic parameters of the HFMBs are obtained by summing the stiffness and damping coefficients of GFBs and AMBs. 


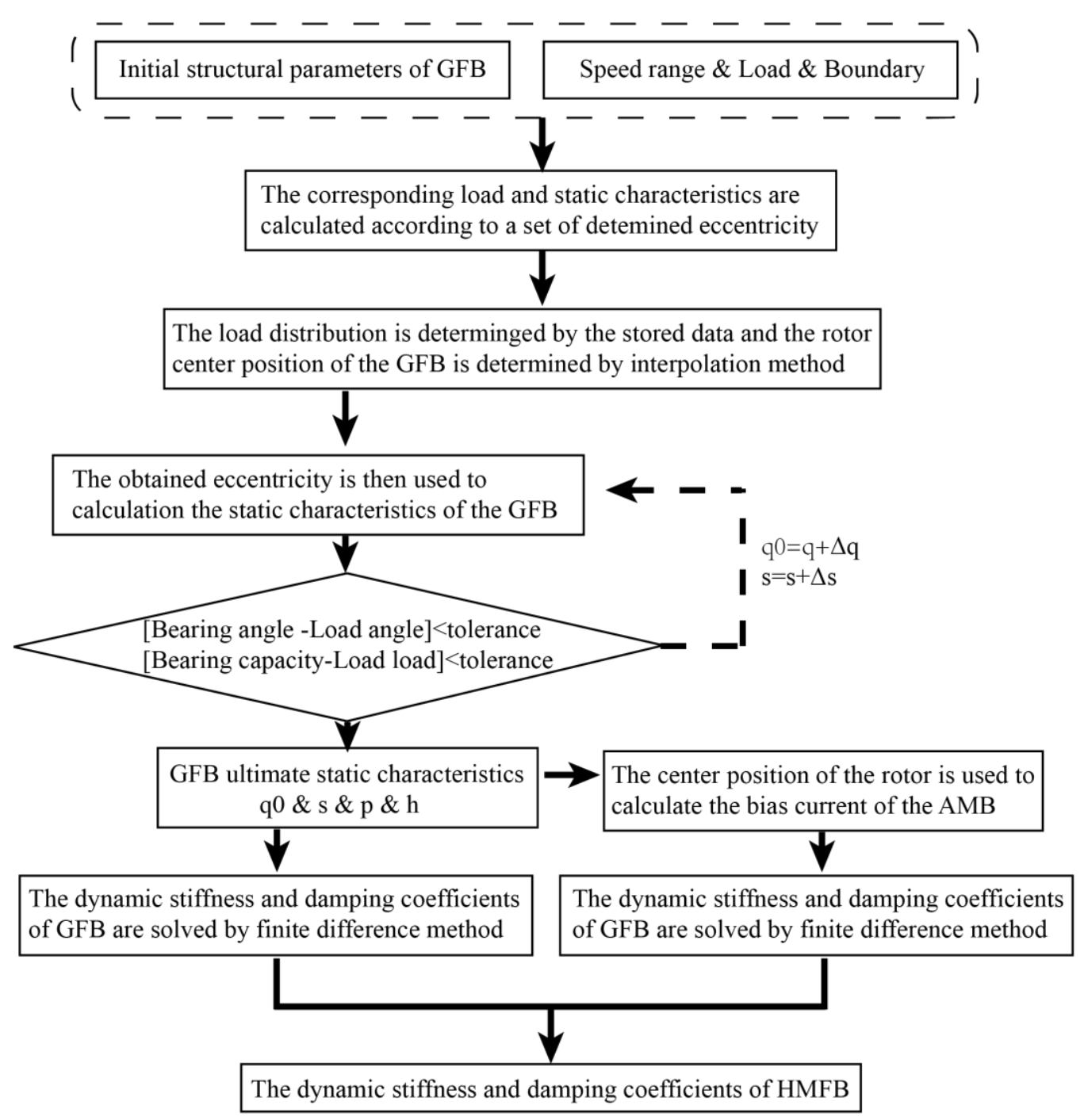

Fig. 9. Flowchart for calculating static and dynamic parameters of HFMBs

According to the calculation results of static characteristics of GFBs and AMBs, the calculation process of dynamic characteristics of HFMBs can be further deduced. The perturbation method is used to solve the dynamic performance of GFBs. When the journal is subjected to small disturbance, the new gas film force is expanded by Taylor series at the equilibrium position, and the following formula is obtained [44]. 
$\left\{\begin{array}{l}F_{A x} \\ F_{A y}\end{array}\right\}=\left\{\begin{array}{c}F_{A x 0} \\ F_{A y 0}\end{array}\right\}+\frac{\partial}{\partial x}\left\{\begin{array}{l}F_{A x 0} \\ F_{A y 0}\end{array}\right\} \Delta x+\frac{\partial}{\partial y}\left\{\begin{array}{c}F_{A x 0} \\ F_{A y 0}\end{array}\right\} \Delta y+\frac{\partial}{\partial \dot{x}}\left\{\begin{array}{c}F_{A x 0} \\ F_{A y 0}\end{array}\right\} \Delta \dot{x}+\frac{\partial}{\partial \dot{y}}\left\{\begin{array}{c}F_{A x 0} \\ F_{A y 0}\end{array}\right\} \Delta \dot{y}$ $+o\left(\Delta x^{2}, \Delta y^{2}, \Delta \dot{x}^{2}, \Delta \dot{y}^{2}\right)$

(10)

As the perturbation term $\Delta x, \Delta y 、 \Delta \dot{x} 、 \Delta \dot{y}$ approaches zero, $o\left(\Delta x^{2}, \Delta y^{2}, \Delta \dot{x}^{2}, \Delta \dot{y}^{2}\right)$ is an infinitely small quantity of higher order and Eq. (10) can be reduced to a linear equation.

$\left[\begin{array}{ll}K_{A x x} & K_{A x y} \\ K_{A y x} & K_{A y y}\end{array}\right]=\left[\begin{array}{ll}\frac{\partial F_{A x 0}}{\partial x} & \frac{\partial F_{A x 0}}{\partial y} \\ \frac{\partial F_{A y 0}}{\partial x} & \frac{\partial F_{A y 0}}{\partial y}\end{array}\right]$

$\left[\begin{array}{ll}D_{A x x} & D_{A x y} \\ D_{A y x} & D_{A y y}\end{array}\right]=\left[\begin{array}{ll}\frac{\partial F_{A x 0}}{\partial \dot{x}} & \frac{\partial F_{A x 0}}{\partial \dot{y}} \\ \frac{\partial F_{A y 0}}{\partial \dot{x}} & \frac{\partial F_{A y 0}}{\partial \dot{y}}\end{array}\right]$

The supporting characteristics of the electromagnetic system depend on the control system. By taking the Laplace transform of the electromagnetic force and substituting the transfer function of the controller, the generalized stiffness of the electromagnetic system can be obtained.

$K(j \omega)=\frac{\frac{C_{c u r}}{j \omega}-F_{x}(j \omega)}{X(j \omega)}=\left(k_{i x 1}+k_{i x 2}\right) c_{p}-\left(k_{x x 1}+k_{x x 2}\right)+j\left(k_{i x 1}+k_{i x 2}\right)\left(c_{d} \omega+\frac{c_{i}}{\omega}\right)$ 
Eq. (13) establishes the functional relationship between the time domain stiffness and damping of electromagnetic system according PID controller gains. The real part and imaginary part of the frequency domain stiffness is generally considered as the time domain stiffness and time domain damping separately.

$$
\left\{\begin{array}{l}
k_{m x}=\left(k_{i x 1}+k_{i x 2}\right) c_{p}-\left(k_{x x 1}+k_{x x 2}\right) \\
D_{m x}=\left(k_{i x 1}+k_{i x 2}\right)\left(c_{d} \omega+\frac{c_{i}}{\omega}\right)
\end{array}\right.
$$

In order to simplify the calculation, the coupling effect between the force along $X$ and $Y$ direction in AMBs is neglected. Therefore, the dynamic stiffness and damping coefficients of HFMBs are the superposition of stiffness and damping of AMBs and GFBs, which are respectively calculated according to different working states.

$$
\begin{aligned}
& K=\left[\begin{array}{cc}
K_{a x x}+K_{m x} & K_{a x y} \\
K_{a y x} & K_{a y y}+K_{m y}
\end{array}\right] \\
& D=\left[\begin{array}{cc}
D_{a x x}+D_{m x} & D_{a x y} \\
D_{a y x} & D_{a y y}+D_{m y}
\end{array}\right]
\end{aligned}
$$

\section{Case Study—Parametric discussion}

A set of stand conditions of HFMBs structure and PID controller gains are given in Table 1 . The film thickness varies in both the $\theta$ and $z$ directions due to the nature of GFBs, and the gap between rotor and magnetic bearing only depends on the rotor position. This makes it easy to understand the relationship between static and dynamic performance on account of the different impacting way on the rotor. The film thickness 
is the performance of the load capacity relating to the complaint surface forced by dynamic pressure, which has no direct relationship with AMBs gap.

Tab.1 Calculation structure and parameters of HFMBs

\begin{tabular}{|c|c|}
\hline \multicolumn{2}{|l|}{ Gas foil bearing (GFB) } \\
\hline Bearing length & $40 \mathrm{~mm}$ \\
\hline Bearing housing radius & $30 \mathrm{~mm}$ \\
\hline Top foil thickness & $0.1 \mathrm{~mm}$ \\
\hline Bump foil thickness & $0.1 \mathrm{~mm}$ \\
\hline Bump pitch & $3.9 \mathrm{~mm}$ \\
\hline Bump half length & $1.55 \mathrm{~mm}$ \\
\hline Bump height & $0.4 \mathrm{~mm}$ \\
\hline \multicolumn{2}{|l|}{ Active magnetic bearing (AMB) } \\
\hline Bias current & $0.5 \mathrm{~A}$ \\
\hline Area of gap & $202 \mathrm{~mm}^{2}$ \\
\hline Coil turns & 198 \\
\hline Air gap thickness & $0.8 \mathrm{~mm}$ \\
\hline$K_{p}$ & 1.70 \\
\hline$K_{i}$ & 7.60 \\
\hline$K_{d}$ & 0.035 \\
\hline
\end{tabular}

The specific load capacity of the AMBs is considered to be a definite value. This helps to analyze the hybrid operation principle rather than to 
focus on the load capacity the two bearings. Three typical work scopes, shown in Tab. 2, illustrate active adaptation of HFMBs in variable work situation by adjusting the static and dynamic performance. The alterable operation mode depending on the work state and the active adjustment of the sharing ratio.

Tab. 2 Operation point and corresponding work scope for the case studies

\begin{tabular}{|c|c|c|}
\hline $\begin{array}{l}\text { Work } \\
\text { scope }\end{array}$ & $\begin{array}{l}\text { Operation } \\
\text { condition }\end{array}$ & Illustration \\
\hline 2 & $\begin{array}{c}\text { Load }=8 \mathrm{~N} ; \\
\text { Speed }=30 \mathrm{krpm}\end{array}$ & $\begin{array}{l}\text { It is the most commonly used scope on account of adoptable three } \\
\text { different operation mode and excellent low speed suspension with } \\
\text { AMBs. }\end{array}$ \\
\hline 5 & $\begin{array}{c}\text { Load }=15 \mathrm{~N} ; \\
\text { Speed }=35 \mathrm{krpm}\end{array}$ & $\begin{array}{l}\text { The magnetic force of AMBs can be the supplement of } \\
\text { hydrodynamic pressure of GFBs for the reason of the rotor mass } \\
\text { beyond the capacity of AMBs. }\end{array}$ \\
\hline 6 & $\begin{aligned} \text { Load } & =12 \mathrm{~N} \\
\text { Speed } & =42 \mathrm{krpm}\end{aligned}$ & $\begin{array}{l}\text { Another way of improving stability of the bearing is using } \\
\text { magnetic force to increase the rotor mass. }\end{array}$ \\
\hline
\end{tabular}

\subsection{Operation point in scope 2}

\section{Static characteristics}




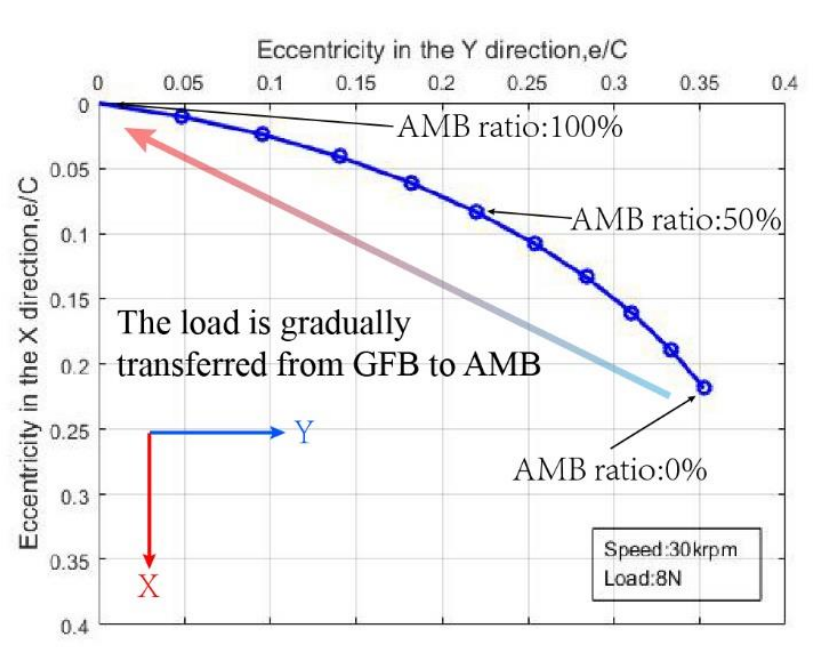

Fig. 10 Eccentricity versus different sharing ratio for HFMBs

（rotational speed:30kprm, total load:8N）

Fig. 10 shows the variation trend of rotor center according to the change of AMBs load ratio. The rotational speed of the bearing is $30 \mathrm{krpm}$ and the total load is $8 \mathrm{~N}$, which is in scope 2 . With the increase of the load ratio of $\mathrm{AMBs}$, the rotor center is gradually approaching the bearing center from eccentric position. When AMBs load ratio is 0 , the rotor is located at the position with the maximum eccentricity and the load is completely loaded by GFBs. In comparison, when AMBs load ratio is 1, the rotor is at bearing center and the load is completely loaded by AMBs. Adjusting the sharing load ratio is bound to change the load supported by GFBs and result in the deviation of the rotor center. Therefore, the determination of the rotor center of HFMBs depends on the load of GFBs. 

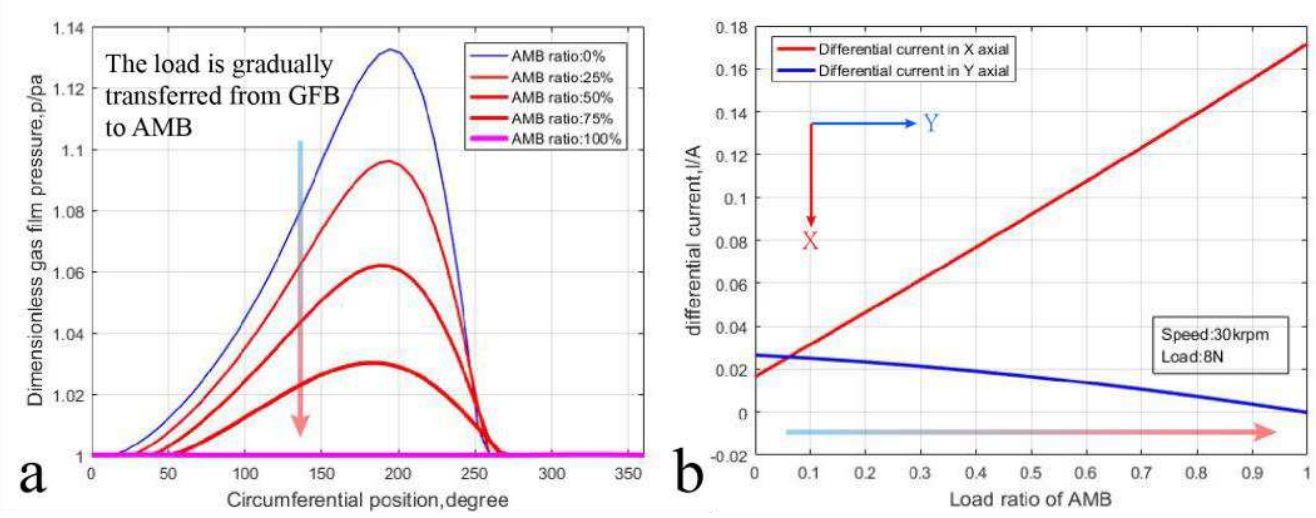

Fig. 11 Air film pressure along the circumferential direction versus AMBs load

ratio (a),

\section{differential current along $X / Y$ direction versus AMBs load ratio (b)}

\section{(rotational speed:30kprm, total load:8N)}

The distribution curve of gas film pressure of HFMBs (on the middle surface) and the variation curve of differential current are shown in Figs. $11 \mathrm{a}$ and $11 \mathrm{~b}$, separately, with different load ratios. It is obvious that the gas film pressure gradually decreases with the increase of AMBs load ratio. As a cooperative component, the differential current along the $X$ direction increases linearly, while the differential current along the $Y$ direction shows a parabola descent. The differential current in both directions is slightly greater than zero when AMBs load ratio is zero, which is caused by the eccentricity of rotor. When the rotor reaches the bearing center, the air film pressure is close to the atmospheric pressure in the circumferential direction. Owing to the $X$ direction differential current generates a separate load on the rotor, the differential current along the $X$ direction reaches its maximum, and the differential current 
along the $Y$ direction drops to zero. The significance of static parameters lies in that the rotor center can indirectly reflect HFMBs dynamic property in real time so as to modify and adjust the load sharing ratio.

\section{Dynamic characteristics}

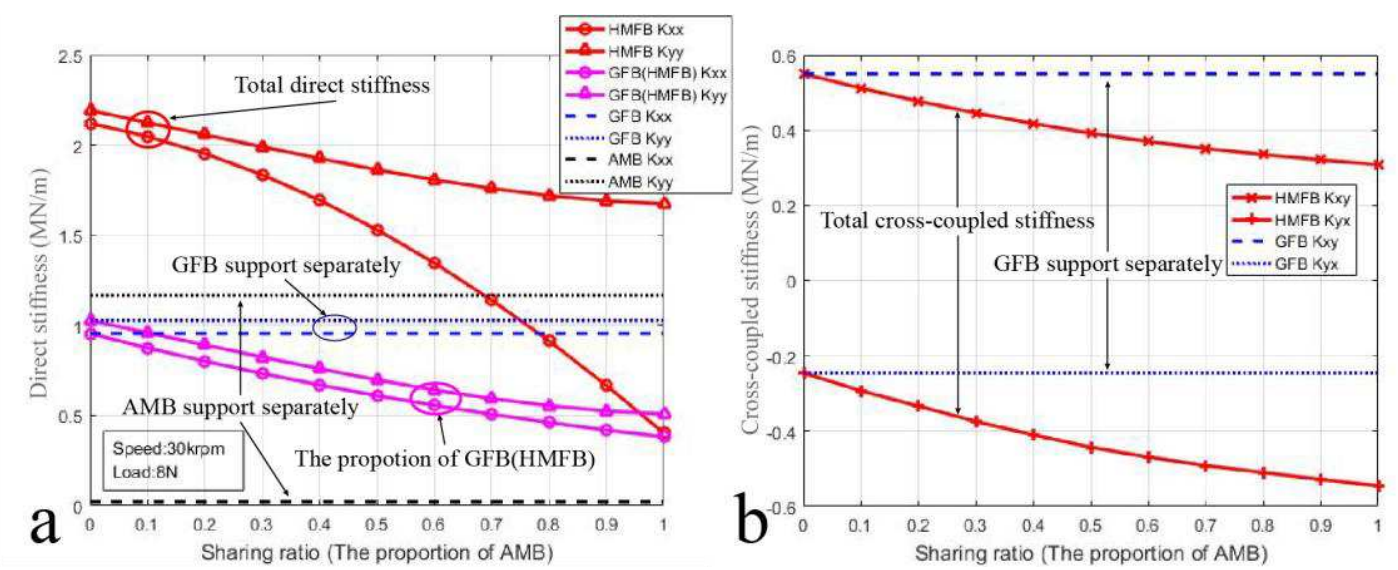

Fig.12. Dynamic direct stiffness (a) and dynamic cross-coupled stiffness (b) of

HFMBs versus AMBs load ratio

\section{（rotational speed:30kprm, total load:8N）}

Direct stiffness coefficient and cross-coupled stiffness coefficient of the HFMB (rotational speed: 30krpm, bearing load: 8N) are shown in Fig. 12 with respect to load sharing ratio. The direct stiffness coefficient $K_{x x}$ of HFMBs decreases sharply with the increase of AMBs load ratio, and the direct stiffness coefficient $K_{y y}$ also decreases significantly, as shown in Fig. 12a. On the one hand, the gas film pressure of GFBs will decrease with the increase of AMBs load ratio, which will lead to a decrease in the dynamic stiffness coefficient of GFBs and finally cause the decrease of the total dynamic stiffness coefficient of HFMBs. On the other hand, the 
direct stiffness of AMBs increases with the increase of force/current factor and decreases with the increase of forceldisplacement factor. The increase of force/displacement factor with the increase of AMBs load ratio is slightly greater than force/current factor, therefore, the direct stiffness coefficient of AMBs will also decrease significantly. It is easy to understand the reason that direct dynamic stiffness coefficient of HFMBs along the $X$ direction has a significantly stronger downward trend than that along the $Y$ direction. In addition, the direct stiffness coefficient of the HFMBs along $X$ direction is lower than that of GFBs when AMBs load ratio is exceeding 0.8, while the direct stiffness coefficient of GFBs along $X$ direction is significantly higher than that of AMBs. Therefore, in terms of maximum stiffness of the bearing, the bearing stiffness coefficient of HFMBs is the best when AMBs load ratio is not more than 0.8, followed by GFBs, and finally AMBs. In addition, the direct stiffness coefficient of HFMBs provided by GFBs accounts for an increasing proportion, although the direct stiffness coefficient of GFBs itself is gradually decreasing. The direct stiffness coefficient along the $Y$ direction of HFMBs is greater than that of AMBs than that of GFBs. The stiffness coefficient provided by GFBs gradually decreases, but the direct stiffness coefficient provided by AMBs is almost constant.

As can be seen from Fig. 12b, the cross-coupled stiffness coefficient of HFMBs decreases gradually with the increase of AMBs load ratio. Since 
the cross-coupled stiffness coefficient of AMBs is neglected, the instability of HFMBs can be attributed to GFBs. It is an understandable fact that the instability factor of HFMBs is reduced because GFBs bears less load. Both direct stiffness coefficient and cross-coupled stiffness coefficient of HFMBs decrease with the increase of AMBs load ratio.

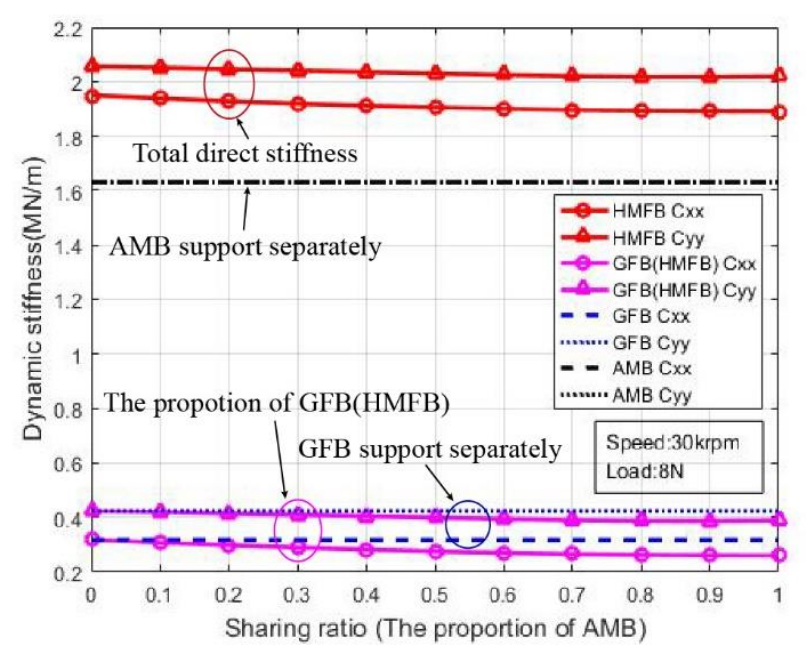

Fig. 13. Dynamic direct damping of HFMBs varies with AMBs load ratio (rotational speed: $30 \mathrm{kprm}$, total load: $8 \mathrm{~N}$ )

Direct dynamic damping coefficient of HFMBs at the operation point (rotational speed $30 \mathrm{krpm}$, bearing load $8 \mathrm{~N}$ ) when different load sharing ratio are adopted, as shown in Fig. 13. The diagram illustrates the change of direct dynamic damping coefficient of HFMBs with AMBs load ratio, and compares with that of GFBs and AMBs. Direct damping coefficient of HFMBs decreases slightly with the increase of AMBs load ratio because of direct damping coefficient of GFBs is decrease, which means that stability of HFMBs increases with the increase of AMBs load ratio as the slight damping coefficient drop is negligible. When AMBs load ratio 
is 0 , the direct stiffness coefficient is the maximum as well as the cross-coupled stiffness coefficient. Since increasing AMBs load ratio cannot decrease the direct damping coefficient obviously but will reduce the direct stiffness coefficient of HFMBs, the optimal load sharing strategy of HFMBs should be around 0.8 considering direct stiffness and stability. Another distinct phenomenon is that when AMBs suspension the rotor separately, the direct damping coefficient $C_{x x}$ and $C_{y y}$ are almost identical, which is completely different from the changing trend of direct dynamic stiffness coefficient.

\subsection{Operation point in scope 5}

\section{Static characteristics}

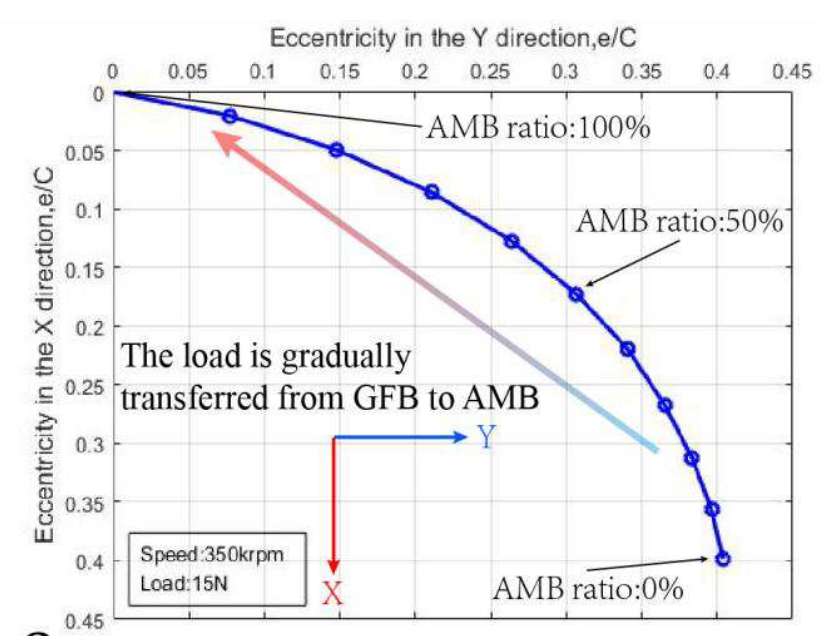

a 

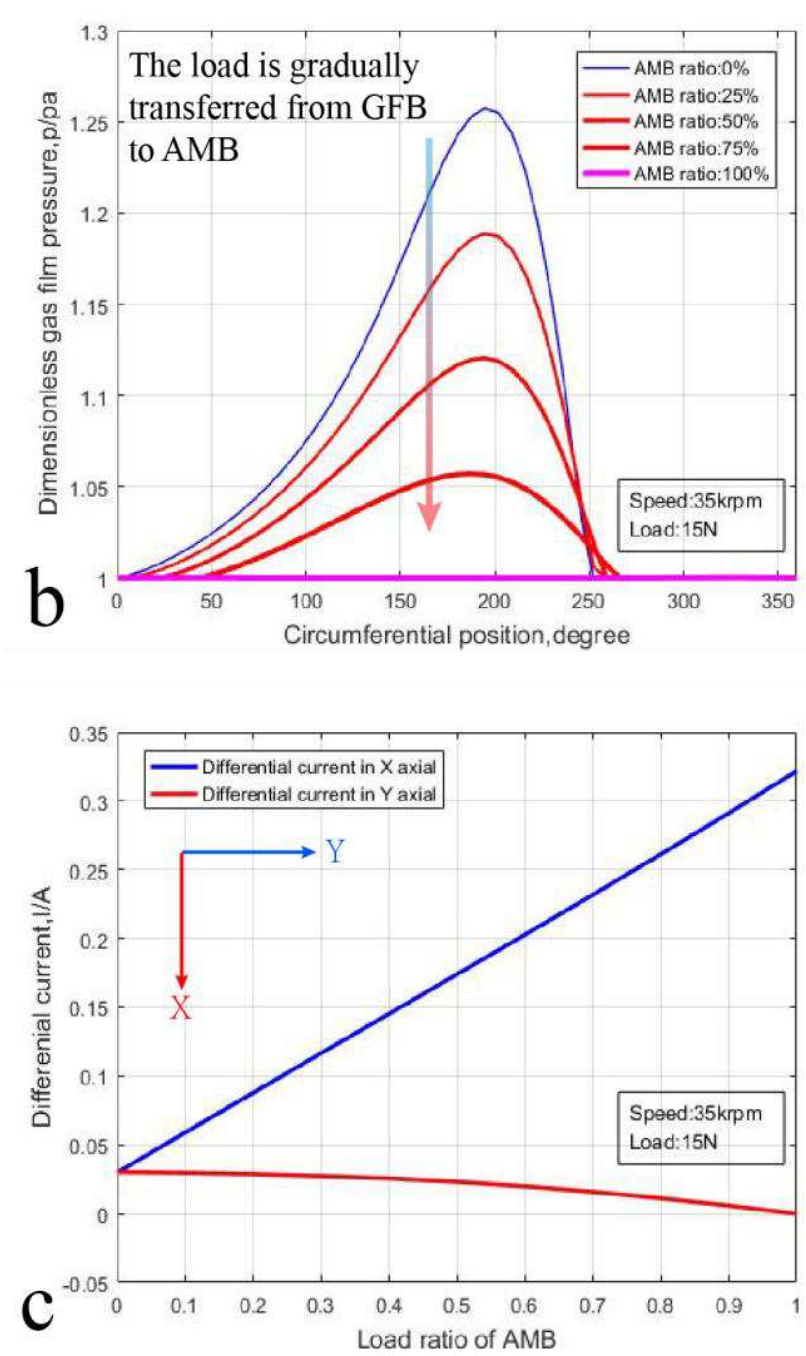

Fig. 14. Variation trend of rotor center (a), air circumferential film pressure (b), and differential current in $X / Y$ directions versus AMBs load ratio (c)

\section{(rotational speed:35kprm, total load:15N)}

Fig.14 describes the static characteristics of HFMBs in scope 5. The corresponding rotational speed is $32 \mathrm{krpm}$ and the load is $15 \mathrm{~N}$. The static performance of the bearing in scope 5 is extremely similar to that in scope 2. The static characteristics reflect the load sharing strategy of 
HFMBs, and it will not substantially change with the change of working condition.

\section{Dynamic characteristics}
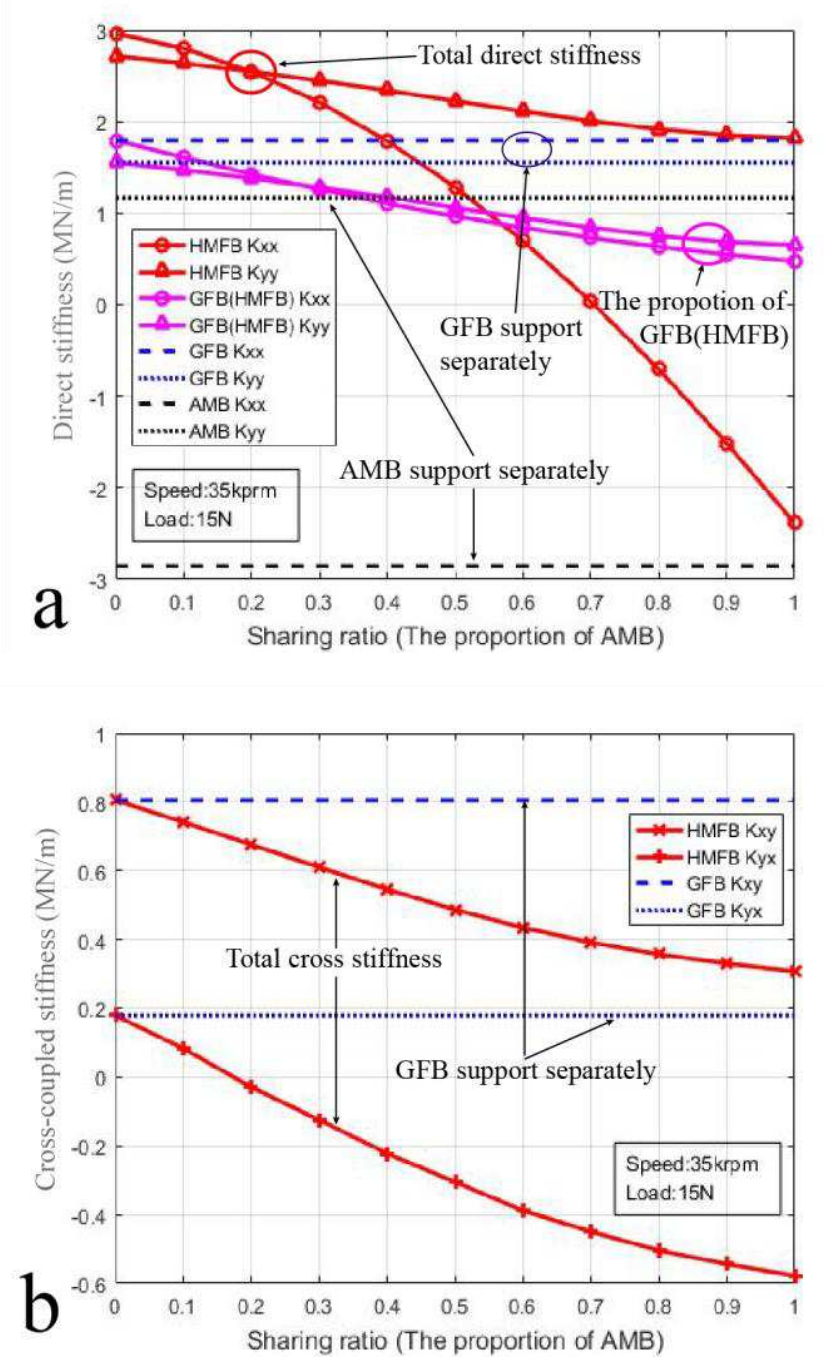


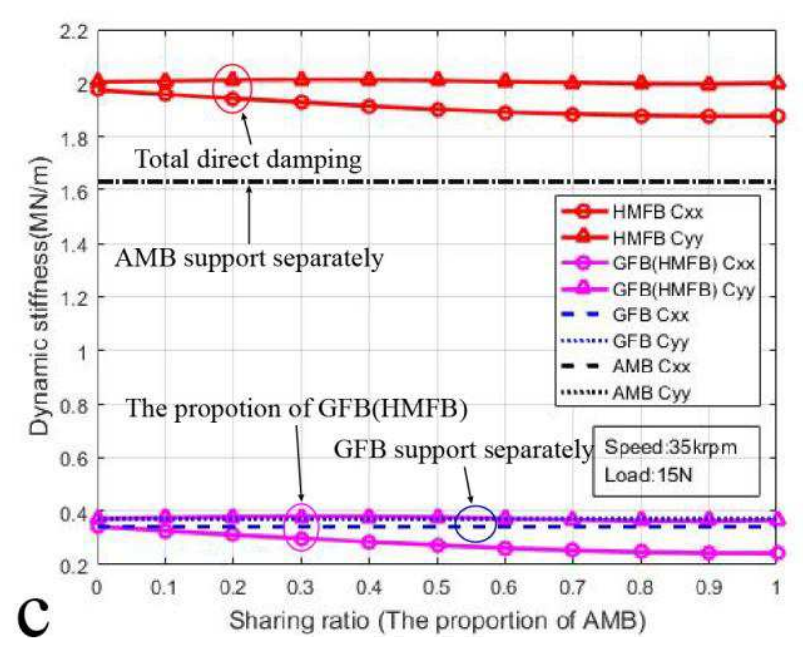

Fig. 15. Dynamic direct stiffness (a), dynamic cross-coupled stiffness (b),

\section{dynamic direct damping (c) of HFMBs versus AMBs load ratio}

\section{(rotational speed:35kprm, total load:15N)}

Fig. 15 presents the direct stiffness coefficient, cross-coupled stiffness coefficient and direct damping coefficient versus AMBs load ratio in scope 5 (rotational speed $35 \mathrm{krpm}$, bearing load $15 \mathrm{~N}$ ). The main difference with scope 2 is that the direct stiffness coefficient of HFMBs along the $X$ direction turns negative when AMBs load ratio exceeds 0.7. When AMBs shows negative stiffness coefficient, the influence of force/displacement factor is significantly greater than that of force/current factor which is a nature of AMBs itself. The direct stiffness of HFMBs is greatly affected by the PID controller gains, so the change of eccentricity and AMBS load require the corresponding PID controller gains. The maintenance of constant PID controller gains will lead to lower direct stiffness coefficient or even negative stiffness coefficient of the bearing. However, the influence of PID controller gains on direct damping 
coefficient of HFMBs is not obvious. Compared with GFBs and AMBs, the HFMB (load ratio of AMB is less than 0.4) have the maximum stiffness coefficient along the $\mathrm{X}$ direction. The optimal load sharing ratio in scope 5 is around 0.4 of AMBs which is quite different from that of HFMBs in scope 2.

\subsection{Operation point in scope 6}

\section{Static characteristics}
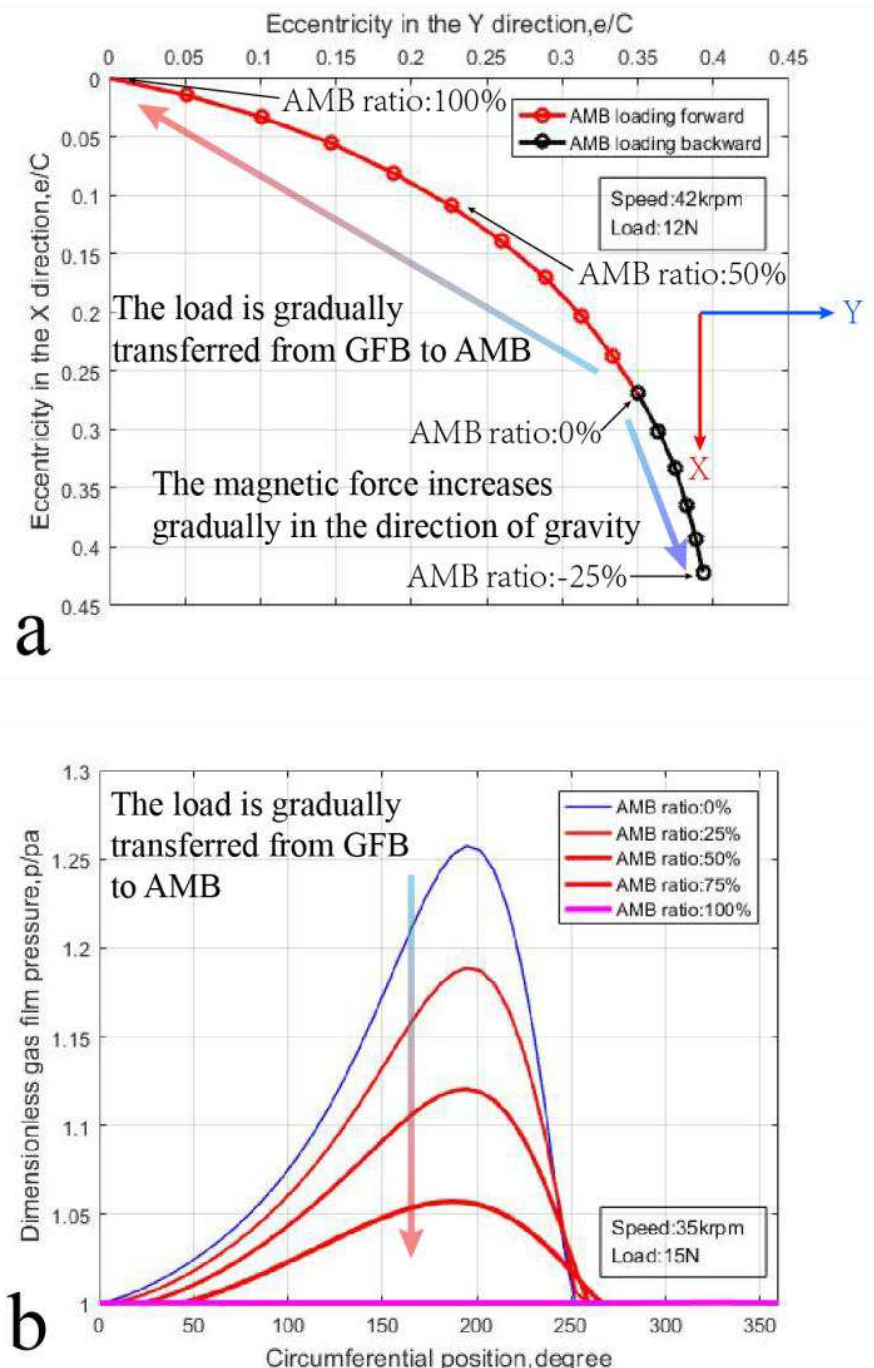


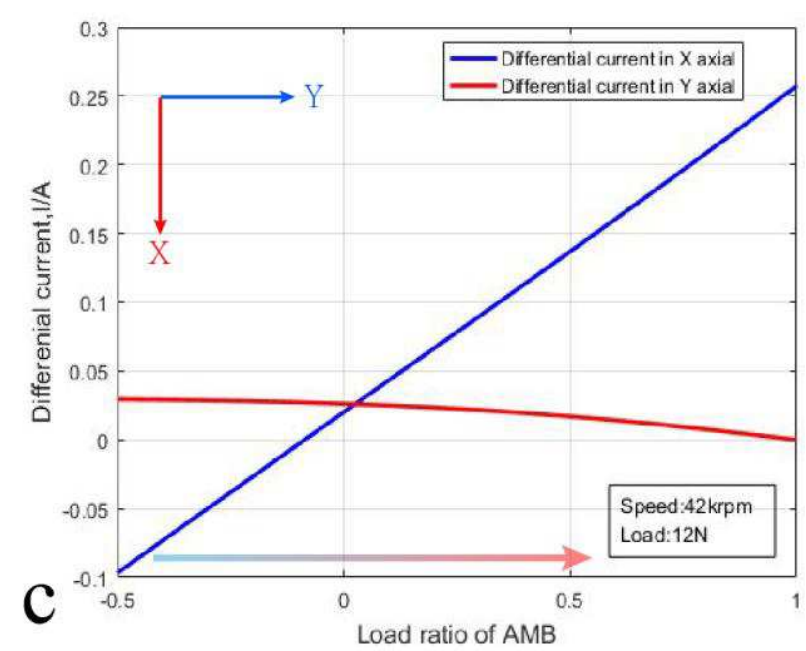

Fig. 16 Eccentricity (a),

air circumferential film pressure (b),

and differential current in $X / Y$ directions versus AMBs load ratio (c),

(rotational speed:42kprm, total load:12N)

Fig. 16 describes the static characteristics of HFMBs in scope 6. The rotational speed is $42 \mathrm{krpm}$ and the load is $12 \mathrm{~N}$. When the magnetic force provides a positive load, the rotor center gradually approaches the bearing center with the increase of AMBs load ratio, which is the same as other operation points. However, when the magnetic force provides a reverse load to enhance the rotor mass, the rotor center gradually moves away from the bearing center with the increase of AMBs load ratio. In both cases, the center trajectory of the rotor together forms a complete curve. In Fig. 16b and Fig. 16c, corresponding to Fig. 16a, the gas film pressure of HFMBs independently supporting the rotor is further increased due to the reverse loading of magnetic force. When the 
magnetic force act in opposite way, the differential current along the $X$ direction also changes from positive to negative, while the differential current along the $Y$ direction still shows a parabolic decline. It can be concluded that using the magnetic force to increase the rotor mass is actually an extended application of the original operation mode.

\section{Dynamic characteristics}
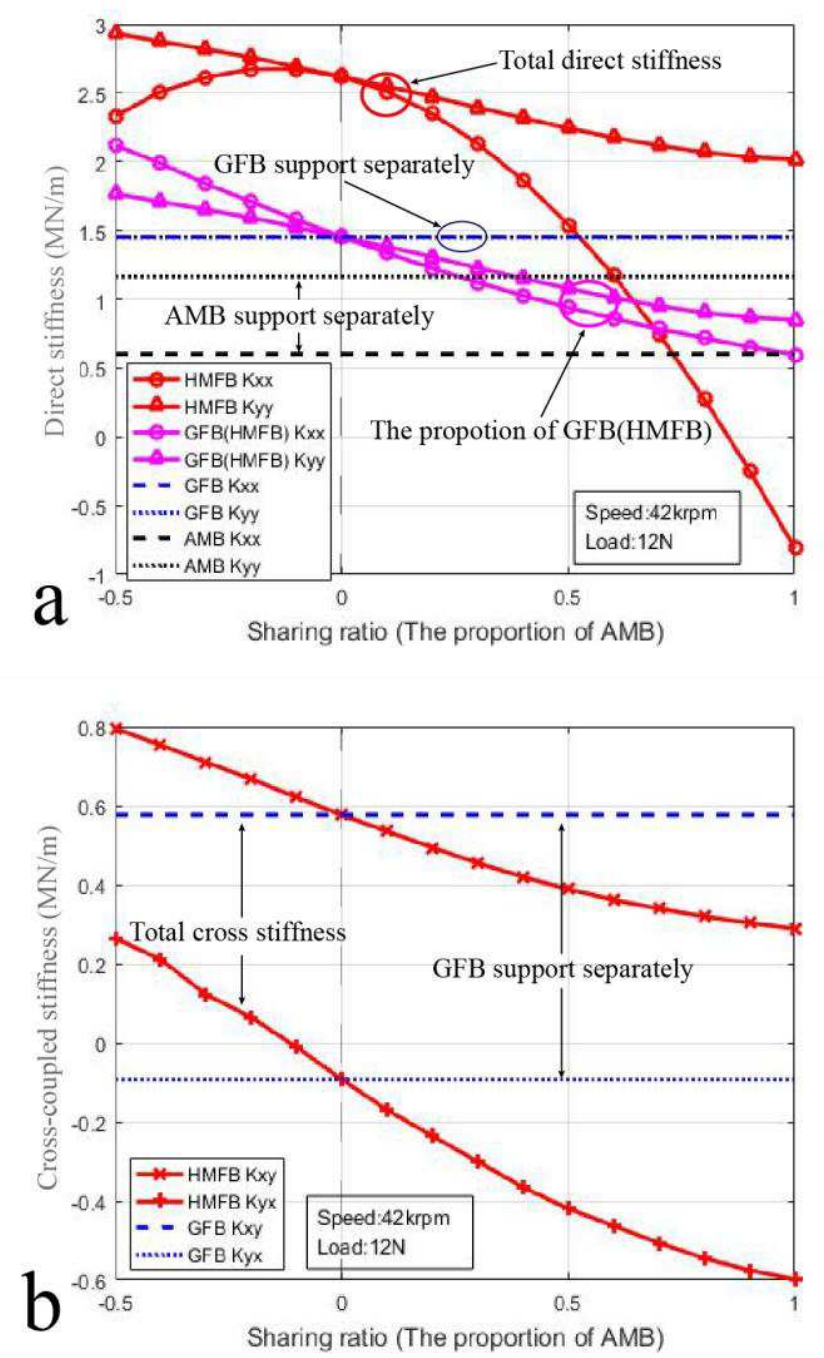


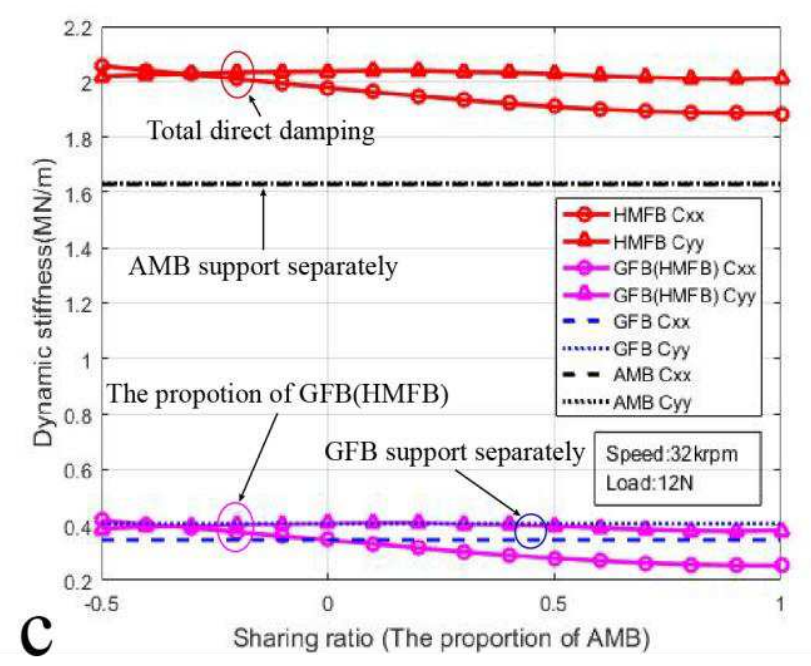

Fig. 17. Dynamic direct stiffness (a), dynamic cross stiffness (b), dynamic

direct damping (c) of HFMBs varies with AMBs load ratio

(rotational speed:42kprm, total load:12N)

Fig. 17 describes the dynamic characteristics of HFMBs with different load sharing strategies in scope 6 . The stiffness and damping coefficient of bearings supported by GFBs or AMBs separately are also added for comparison. As can be seen from Fig. 17a, when AMBs provide a positive effect, its direct stiffness coefficient curve changes with the load ratio similar to that of the first two operation points. The direct stiffness coefficient along $X$ and $Y$ direction decreases with the increase of AMBs load ratio. However, when AMBs act the opposite way, the direct stiffness coefficient along the $X$ direction shows a short rise followed by a rapid decline, while the direct stiffness along the $Y$ direction keeps rising. The maximum value of the direct stiffness coefficient along $X$ direction occurs when AMBs load ratio is around -0.1 . The reason is that the rise of differential current of AMBs will reduce the stiffness 
coefficient, even if it is an opposite effect of the magnetic force. Therefore, there is always a maximum value for the direct stiffness coefficient of HFMBs along the $X$ direction. The increase of AMBs load in the opposite way will continuously increase the stiffness coefficient of GFBs, but also decrease the stiffness coefficient of AMBs. In addition, the range of direct stiffness coefficient available for HFMBs in this diagram is between -0.5 and 0.5 . AMBs further expand the control scope of load sharing strategy of HFMBs by increasing the rotor mass in reality. From Fig. 17b and Fig. 17c, it can be seen that the cross-coupled stiffness coefficient of HFMBs decreases continuously with the increase of AMBs load ratio. Meanwhile, the direct damping coefficient of HFMBs along the $X$ direction first decreases slightly and then remains stable with the increase of AMBs load ratio, while the direct damping coefficient along the $Y$ direction remains basically unchanged. It can be reasonably inferred from the cross-coupled stiffness coefficient and direct damping coefficient that the optimal load sharing strategy for the stability of HFMBs is 0.5 for AMBs.

\section{Conclusion}

In order to guide the conceptual design of HFMBs, this paper presented a theoretical investigation on operation mode and load sharing strategy with the consideration of bearing stability. Because GFBs and AMBs 
have totally different physical properties and suitable work scope, the hybrid bearing, HFMBs, can be designed into seven possible operation scopes. By cross correlating Reynolds equation, foil structure deflection and magnetic force, a numerical model was presented. The bearing performance is not just determined by the rotational speed and load but also related to the operation mode and load sharing strategy.

Three representative work points were selected to analyze the effect of operation modes and load sharing strategies on HFMBs performance. The prediction results showed that the differential current of AMBs should be determined according to the rotor position of GFBs and the load sharing ratio. With the increase of AMBs load ratio, the rotor center gradually moved from the eccentric position to the bearing center. The HFMBs with right load sharing strategy shows better stability and wider operation range (speed and load) than that of GFBs and AMBs. The predictions showed that the optimal load sharing ratio of AMBs in scopes 2, 5 and 6 are $0.8,0.4$ and 0.5 , respectively. In addition, the prediction results show that adjusting the load sharing while ensuring the same PID controller gains will result in negative direct stiffness of HFMBs. Meanwhile, In addition, the HFMBs with opposite magnetic force can further improve the direct stiffness.

In the following work, a test rig supported by HFMBs will be built and the influence of PID controller gains on the performance of HFMBs will 
be discussed.

\section{Acknowledgements}

Not applicable

\section{Authors' contributions}

KF was in charge of the whole analyses and revised the final manuscript;

$\mathrm{HZ}$ wrote the whole manuscript, completed the simulation analyses and drawings; QY, HG, YC assisted with simulation analyses. All authors read and approved the final manuscript.

\section{Authors' Information}

Kai Feng, born in 1982, is currently a professor and a $\mathrm{PhD}$ candidate supervisor at State Key Laboratory of Advanced Design and Manufacturing for Vehicle Body, Hunan University, China. He received his $\mathrm{PhD}$ degree from the University of Tokyo, Japan, in 2009. His research interests include intelligent gas foil bearing technology, ultra high speed gas lubrication, flexible robot technology, ultra high speed rotating machinery.

Hang Zhang, born in 1989 , is currently a $\mathrm{PhD}$ candidate at State Key Laboratory of Advanced Design and Manufacturing for Vehicle Body, Hunan University, China. His research interests include hybrid foil 
magnetic suspension technology, active control of nonlinear rotating system.

Qianwei Yin, born in 1996, is currently a graduate student at Hunan University, China. He received his BE degree from Hunan Universtiy, China, in 2014. His research contents include the control system of hybrid magnetic and foil suspension technology, and DSP software development.

Hanqing Guan, born in 1991, is currently a lecturer at Hunan Institute of Engineering, China. He received the Ph.D. degree in mechanical engineering from Hunan University, China, in 2020. His research interests include the application of active gas bearing, the control of nonlinear rotating system, and the distributed energy equipment.

Yuanlong Cao, born in 1990, is currently a lecturer at University of South China, China. He received the Ph.D. degree in mechanical engineering from Hunan University, China, in 2020. His research interests include application and nonlinear rotordynamics of gas foil bearing and exploration of active gas bearings.

\section{Funding}


Supported by the National Natural Science Foundation of China (Grant No. 51875185), the Foundation of China Academy of Space Technology

(CAST), and the Foundation of Hunan Province (Grant No.2018JJ1006).

\section{Competing interests}

The authors declare that they have no competing interests.

\section{Author Details}

${ }^{1}$ State Key Laboratory of Advanced Design and Manufacturing for Vehicle Body, Hunan University, Changsha 410082, China. ${ }^{2}$ School of Mechanical Engineering, Hunan Institute of Engineering, Xiangtan 411100, China. ${ }^{3}$ College of Mechanical Engineering, University of South China, Hengyang 421000, China. 


\section{References}

[1] H. Heshmat, H. M. Chen, and J. F. Walton, "On the performance of hybrid foil-magnetic bearings," Journal of Engineering for Gas Turbines and Power-Transactions of the Asme, vol. 122, no. 1, pp. 73-81, Jan 2000.

[2] C. DellaCorte, "Oil-Free shaft support system rotordynamics: Past, present and future challenges and opportunities," Mechanical Systems and Signal Processing, vol. 29, pp. 67-76, May 2012.

[3] C. McAuliffe and P. J. Dziorny, "Bearing cooling arrangement for air cycle machine," ed: Google Patents, 1992.

[4] H. Heshmat, J. F. Walton, II, C. D. Corte, and M. Valco, "Oil-Free Turbocharger Demonstration Paves Way to Gas Turbine Engine Applications," in ASME Turbo Expo 2000: Power for Land, Sea, and Air, 2000, vol. Volume 1: Aircraft Engine; Marine; Turbomachinery; Microturbines and Small Turbomachinery, V001T04A008.

[5] K. Ryu, "Oil-free turbocharger bearing assembly having conical shaft supported on compliant gas bearings," ed: Google Patents, 2016.

[6] H. Heshmat, J. F. Walton, II, M. J. Tomaszewski, and Asme, Demonstration of a turbojet engine using an air foil bearing (Proceedings of the ASME Turbo Expo 2005, Vol 1). 2005, pp. 919-926.

[7] S. A. Klusman, "Gas turbine engine, machine and self-aligning foil bearing system," ed: Google Patents, 2017.

[8] S. A. Howard and C. DellaCorte, "Gas foil bearings for space propulsion nuclear electric power generation," 2006.

[9] S. A. Howard, R. J. Bruckner, C. DellaCorte, and K. C. Radil, "Gas foil bearing technology advancements for Closed Brayton Cycle turbines," in Space Technology and Applications International Forum - Staif 2007, vol. 880, M. S. ElGenk, Ed. (AIP Conference Proceedings, 2007, pp. 668-+.

[10] Y.-B. Lee, Y.-S. Kwak, J. T. Chung, and K. Sim, "Microturbocharger with Air Foil Bearings for a 100-W Class Micro Power System and Improvement of Rotordynamic Performance," Tribology Transactions, vol. 54, no. 6, pp. 939-948, 20112011.

[11] C. Dellacorte, "The effects of substrate material and thermal processing atmosphere on the strength of PS304: A high temperature solid lubricant coating," Tribology Transactions, vol. 46, no. 3, pp. 361-368, Jul 2003.

[12] K. Feng, X. Zhao, C. Huo, and Z. Zhang, "Analysis of novel hybrid bump-metal mesh foil bearings," Tribology International, vol. 103, pp. 529-539, Nov 2016.

[13] S. Bouaziz, N. B. Messaoud, M. Mataar, T. Fakhfakh, and M. Haddar, "A theoretical model for analyzing the dynamic behavior of a misaligned rotor with active magnetic bearings," Mechatronics, vol. 21, no. 6, pp. 899-907, Sep 2011.

[14] J. R. Hull, T. M. Mulcahy, K. L. Uherka, R. A. Erck, and R. G. Abboud, "Flywheel energy storage using superconducting magnetic bearings," Applied Superconductivity, vol. 2, no. 7-8, pp. 
449-456, July-Aug. 1994.

[15] G. G. Sotelo, R. de Andrade, and A. C. Ferreira, "Magnetic bearing sets for a flywheel system," leee Transactions on Applied Superconductivity, vol. 17, no. 2, pp. 2150-2153, Jun 2007.

[16] M. Weck, U. Wahner, Cirp, and Cirp, Linear magnetic bearing and levitation system for machine tools (Cirp Annals 1998 - Manufacturing Technology, Vol 47, No 1). 1998, pp. 311-314.

[17] J. H. Lee, P. E. Allaire, G. Tao, J. A. Decker, and X. Zhang, "Experimental study of sliding mode control for a benchmark magnetic bearing system and artificial heart pump suspension," leee Transactions on Control Systems Technology, vol. 11, no. 1, pp. 128-138, Jan 2003.

[18] M. Glauser, W. Jiang, G. X. Li, Z. L. Lin, P. E. Allaire, and D. Olson, "Optimization of an axial flow heart pump with active and passive magnetic bearings," Artificial Organs, vol. 30, no. 5, pp. 400-403, May 2006

[19] M. D. Noh, S. R. Cho, J. H. Kyung, S. K. Ro, and J. K. Park, "Design and implementation of a fault-tolerant magnetic bearing system for turbo-molecular vacuum pump," leee-Asme Transactions on Mechatronics, vol. 10, no. 6, pp. 626-631, Dec 2005.

[20] C. H. Park, S. K. Choi, and S. Y. Ham, Design and control for hybrid magnetic thrust bearing for turbo refrigerant compressor (2011 IEEE International Conference on Automation Science and Engineering). 2011, pp. 792-7.

[21] G. Sun, A. B. Palazzolo, A. Provenza, and G. Montague, "Detailed ball bearing model for magnetic suspension auxiliary service," Journal of Sound and Vibration, vol. 269, no. 3-5, pp. 933-963, Jan 2004.

[22] H. Heshmat, H. M. Chen, and I. J. F. Walton, "Hybrid foil-magnetic bearing," ed: Google Patents, 2002.

[23] E. E. Swanson, H. Heshmat, and J. Walton, "Performance of a foil-magnetic hybrid bearing," Journal of Engineering for Gas Turbines and Power-Transactions of the Asme, vol. 124, no. 2, pp. 375-382, Apr 2002.

[24] S. N. Jeong, T. H. Kim, C. H. Kim, Y. B. Lee, and Asme, VIBRATION CONTROL OF A HIGH SPEED ROTOR SUPPORTED BY THE COMBINED SMART BEARING (Proceedings of the Asme/Stle International Joint Tribology Conference - 2011). 2012, pp. 333-335.

[25] Y. Tian, Y. Sun, L. Yu, and Asme, STEADY-STATE CONTROL OF HYBRID FOIL-MAGNETIC BEARINGS (Proceedings of the Asme Turbo Expo 2012, Vol 7, Pts a and B). 2012, pp. 849-857.

[26] P. Minh Nha and H.-J. Ahn, "Experimental optimization of a hybrid foil-magnetic bearing to support a flexible rotor," Mechanical Systems and Signal Processing, vol. 46, no. 2, pp. 361-372, Jun 32014.

[27] B. Yang, H. Geng, Y. Sun, and L. Yu, "Dynamic characteristics of hybrid foil-magnetic bearings (HFMBs) concerning eccentricity effect," International Journal of Applied Electromagnetics and Mechanics, vol. 52, no. 1-2, pp. 271-279, 20162016.

[28] S. Jeong and Y. B. Lee, "Effects of eccentricity and vibration response on high-speed rigid rotor supported by hybrid foil-magnetic bearing," Proceedings of the Institution of Mechanical Engineers Part C-Journal of Mechanical Engineering Science, vol. 230, no. 6, pp. 994-1006, Apr 2016.

[29] S. Jeong, D. Jeon, and Y. B. Lee, "Rigid Mode Vibration Control and Dynamic Behavior of Hybrid Foil-Magnetic Bearing Turbo Blower," Journal of Engineering for Gas Turbines and Power-Transactions of the Asme, vol. 139, no. 5, May 2017, Art. no. 052501. 
[30] Z. Tian, Z. Wei, Y. Sun, and leee, Nonlinear Adaptive Control For Hybrid Foil-magnetic Bearing (2017 leee International Conference on Mechatronics and Automation). 2017, pp. 81-86.

[31] S. Jeong and Y. B. Lee, "Vibration control of high-speed rotor supported by hybrid foil-magnetic bearing with sudden imbalance," Journal of Vibration and Control, vol. 23, no. 8, pp. 1296-1308, May 2017.

[32] K. K. Basumatary, G. Kumar, K. Kalita, and S. K. Kakoty, "Stability analysis of rigid rotors supported by gas foil bearings coupled with electromagnetic actuators," Proceedings of the Institution of Mechanical Engineers Part C-Journal of Mechanical Engineering Science, 2019, Art. no. Unsp 0954406219877903.

[33] H. Heshmat, W. Shapiro, and S. J. J. o. L. T. Gray, "Development of foil journal bearings for high load capacity and high speed whirl stability," vol. 104, no. 2, pp. 149-156, 1982.

[34] H. Heshmat and C.-P. R. Ku, "Structural Damping of Self-Acting Compliant Foil Journal Bearings," Journal of Tribology, vol. 116, no. 1, pp. 76-82, 1994.

[35] J.-h. Song and D. Kim, "Foil Gas Bearing With Compression Springs: Analyses and Experiments," Journal of Tribology, vol. 129, no. 3, pp. 628-639, 2007.

[36] K. Feng, Y. Cao, K. Yu, H. Guan, Y. Wu, and Z. Guo, "Characterization of a controllable stiffness foil bearing with shape memory alloy springs," Tribology International, vol. 136, pp. 360-371, Aug 2019.

[37] G. Schweitzer and E. H. Maslen, Magnetic bearings: theory, design, and application to rotating machinery. Springer Berlin, 2009.

[38] B. Defoy, T. Alban, and J. Mahfoud, "Experimental Assessment of a New Fuzzy Controller Applied to a Flexible Rotor Supported by Active Magnetic Bearings," Journal of Vibration and Acoustics-Transactions of the Asme, vol. 136, no. 5, Oct 2014, Art. no. 051006.

[39] K. Nonami and T. Ito, "mu synthesis of flexible rotor-magnetic bearing systems," IEEE Transactions on Control Systems Technology, vol. 4, no. 5, pp. 503-12, Sept. 1996.

[40] Y. Wang, J. Fang, and S. Zheng, "A Field Balancing Technique Based on Virtual Trial-Weights Method for a Magnetically Levitated Flexible Rotor," Journal of Engineering for Gas Turbines and Power-Transactions of the Asme, vol. 136, no. 9, Sep 2014, Art. no. 092502.

[41] S. Zheng and R. Feng, "Feedforward compensation control of rotor imbalance for high-speed magnetically suspended centrifugal compressors using a novel adaptive notch filter," Journal of Sound and Vibration, vol. 366, pp. 1-14, Mar 312016.

[42] O. Matsushita, T. Imashima, Y. Hisanaga, and H. Okubo, "Aseismic vibration control of flexible rotors using active magnetic bearing," Journal of Vibration and Acoustics-Transactions of the Asme, vol. 124, no. 1, pp. 49-57, Jan 2002.

[43] M. N. Sahinkaya, A.-H. G. Abulrub, and C. R. Burrows, "An Adaptive Multi-Objective Controller for Flexible Rotor and Magnetic Bearing Systems," Journal of Dynamic Systems Measurement and Control-Transactions of the Asme, vol. 133, no. 3, May 2011, Art. no. 031003.

[44] J.-P. Peng and M. Carpino, "Calculation of Stiffness and Damping Coefficients for Elastically Supported Gas Foil Bearings," Journal of Tribology, vol. 115, no. 1, pp. 20-27, 1993.

[45] D. Kim, "Parametric studies on static and dynamic performance of air foil bearings with different top foil geometries and bump stiffness distributions," Journal of Tribology-Transactions of the Asme, vol. 129, no. 2, pp. 354-364, Apr 2007.

[46] H. Heshmat, J. A. Walowit, and O. Pinkus, "Analysis of Gas-Lubricated Foil Journal Bearings," Journal of Lubrication Technology, vol. 105, no. 4, pp. 647-655, 1983. 

Figures

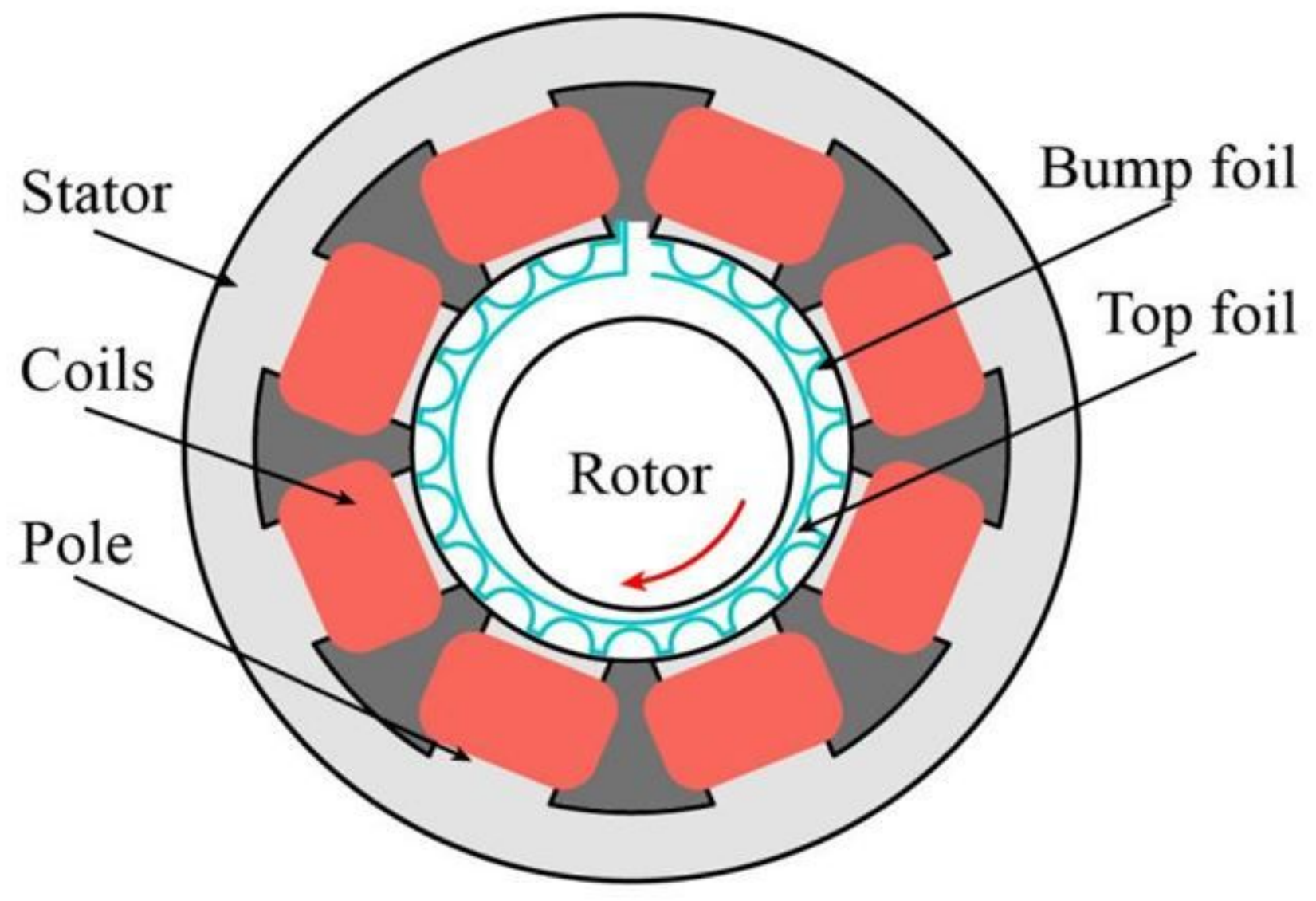

Figure 1

The structure of hybrid foil magnetic bearings 


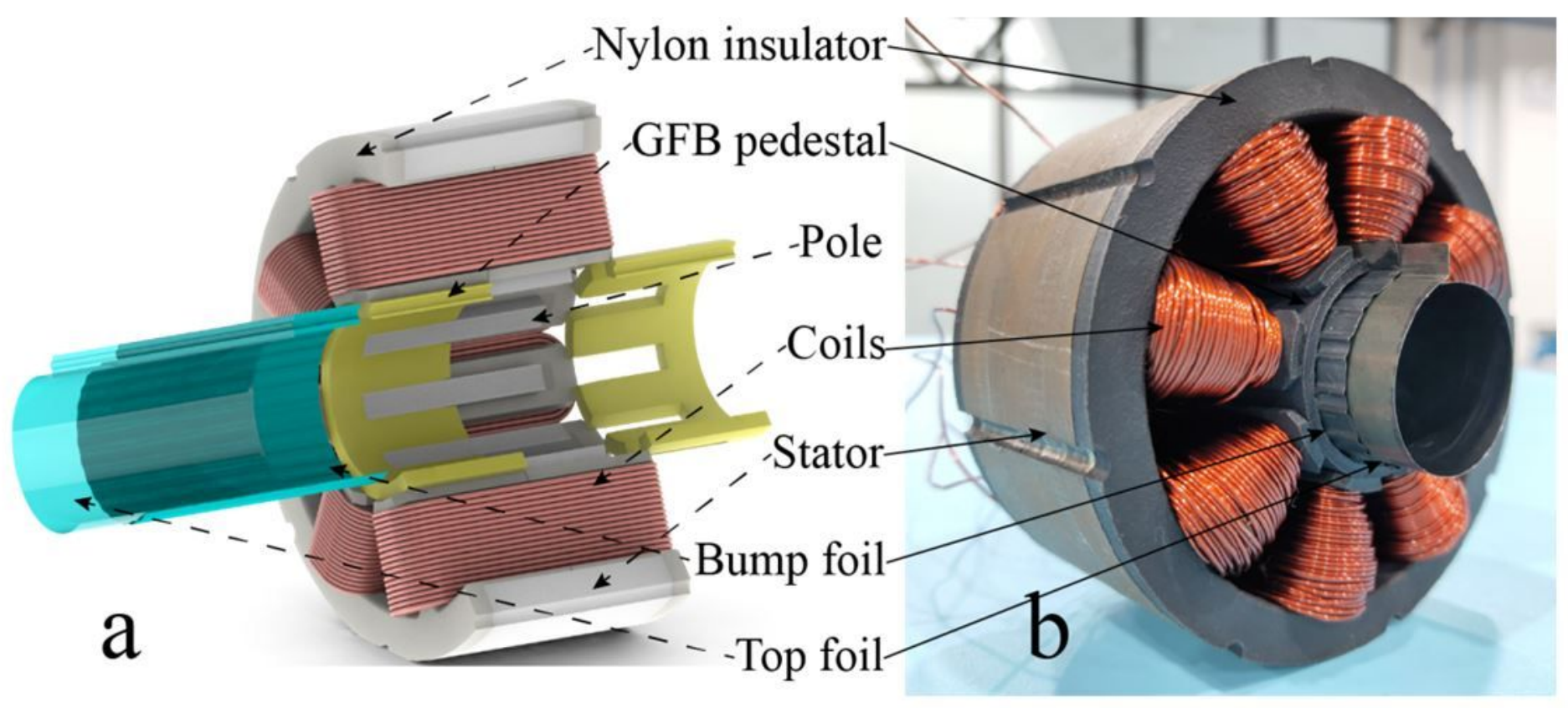

Figure 2

Schematic diagram of HFMBs (a) and photograph of a test bearing (b)
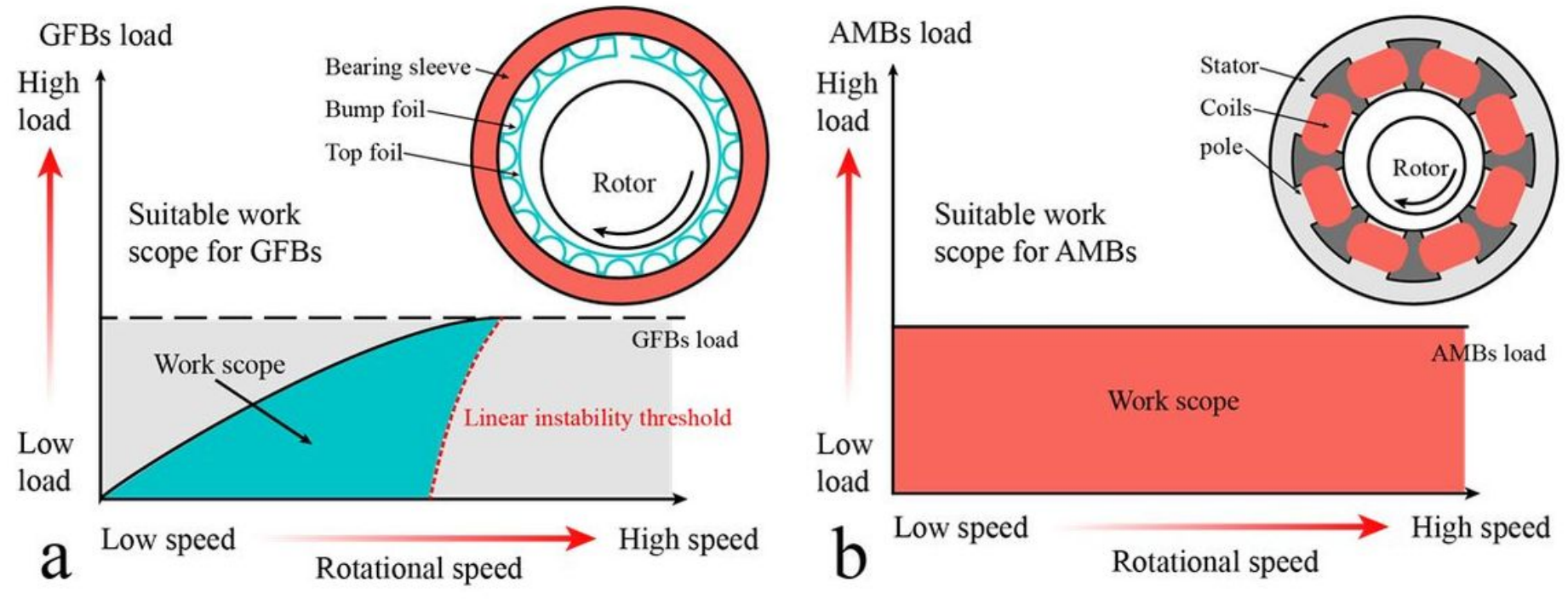

\section{Figure 3}

Suitable work scope of gas foil bearings (a) and active magnetic bearings 
HFMBs load

High $\uparrow$ load

$\uparrow \begin{aligned} & \text { Suitable work } \\ & \text { scope of HFMBs }\end{aligned}$
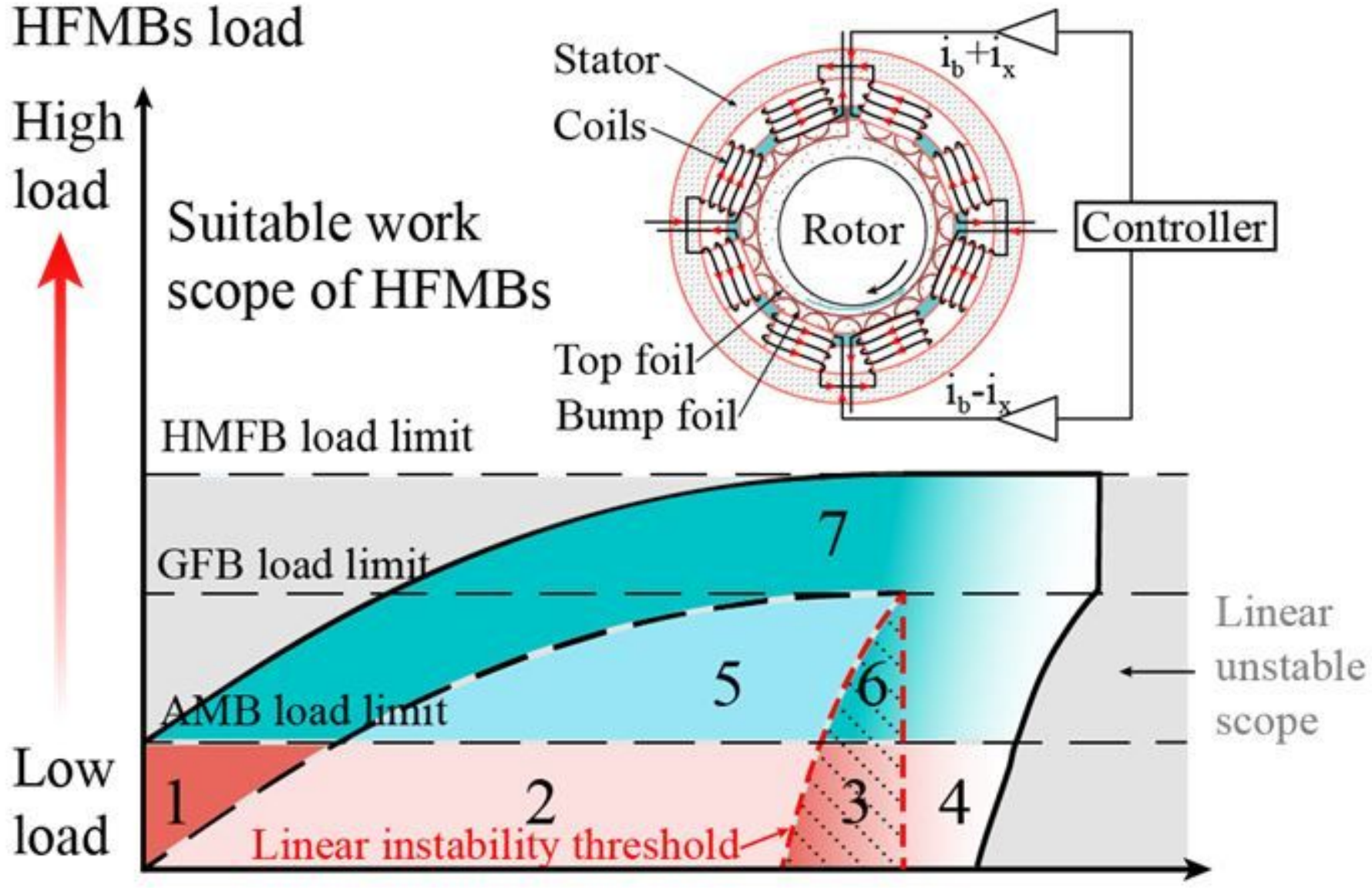

Low speed

\section{HFMBs speed}

Figure 4

Work scope of hybrid foil magnetic bearings

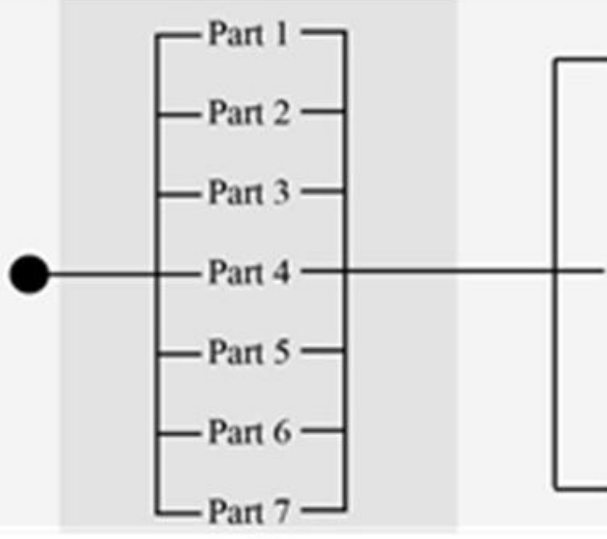

(1)

Work scope
AMBs

HMFBs

AFBs

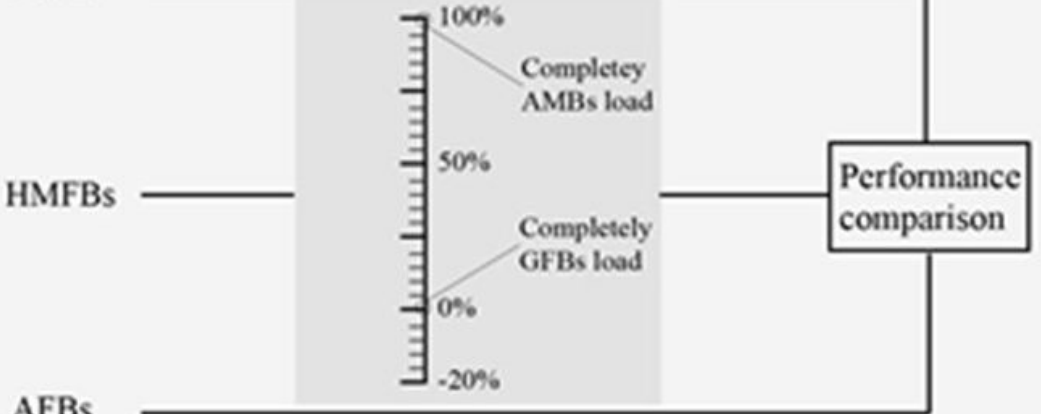

2

Operation mode

High speed 
Figure 5

Specific operation mode of the HFMBs load sharing strategy

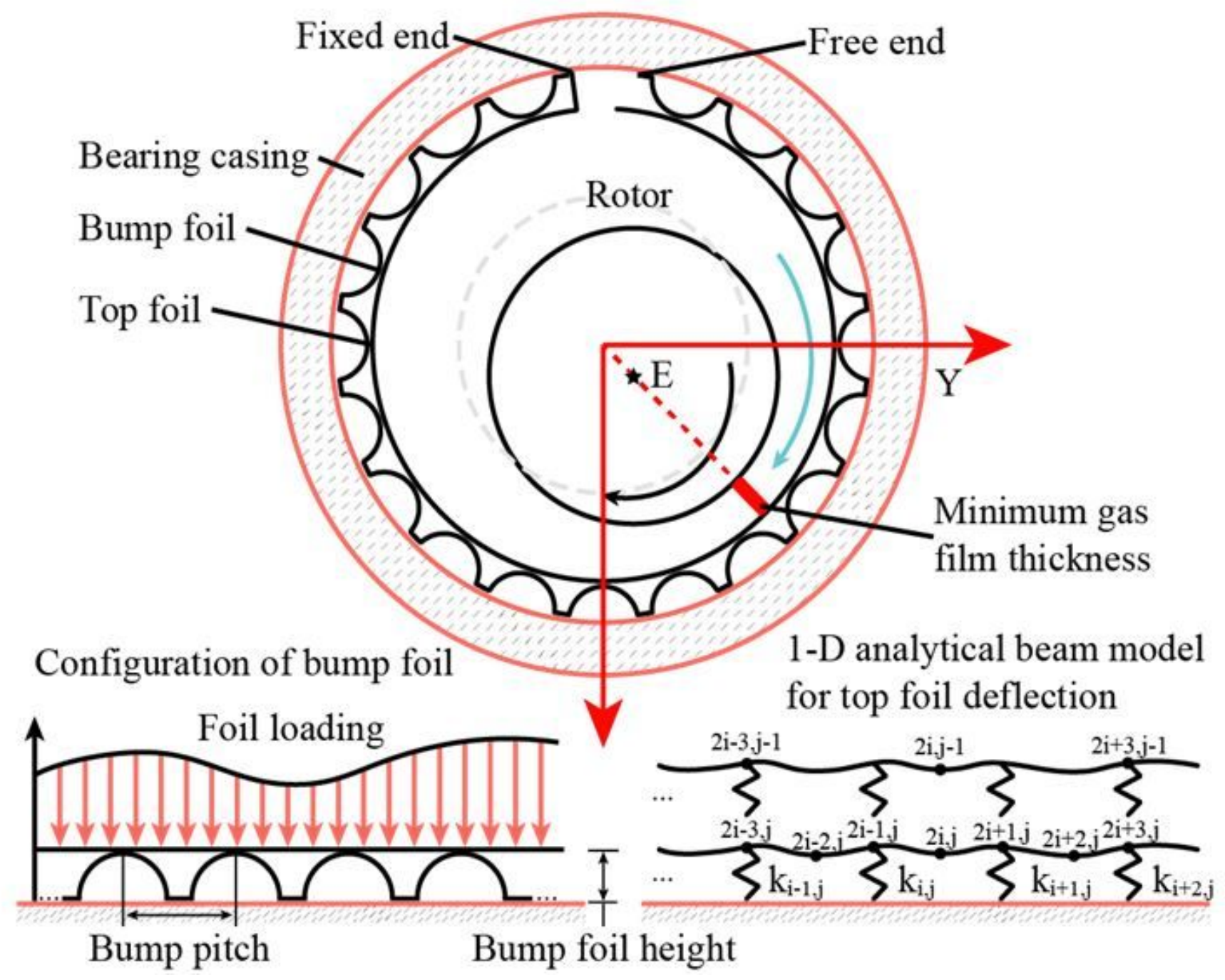

Figure 6

Calculation model of gas foil bearings 


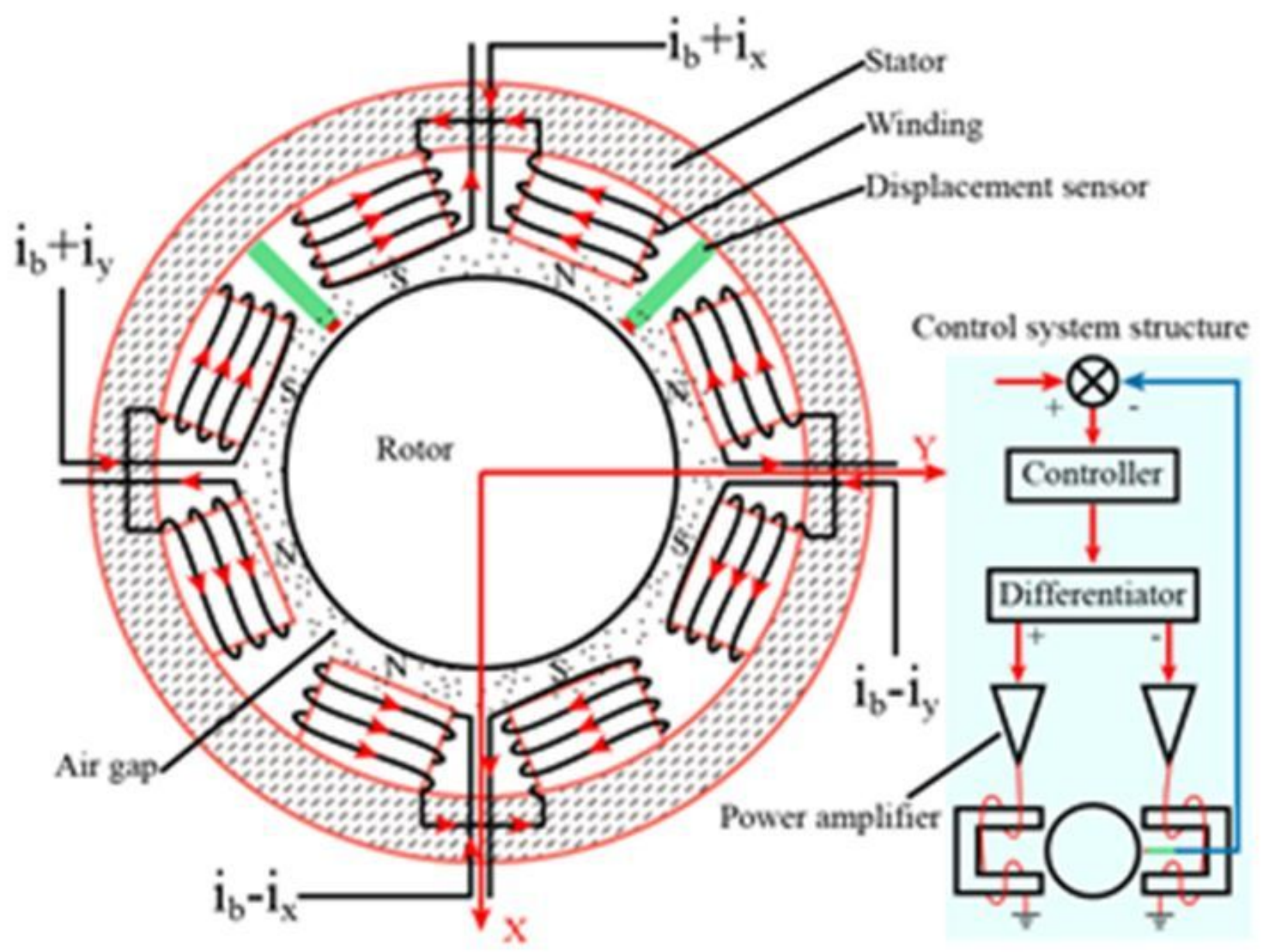

Figure 7

Schematic diagram of active magnetic bearing

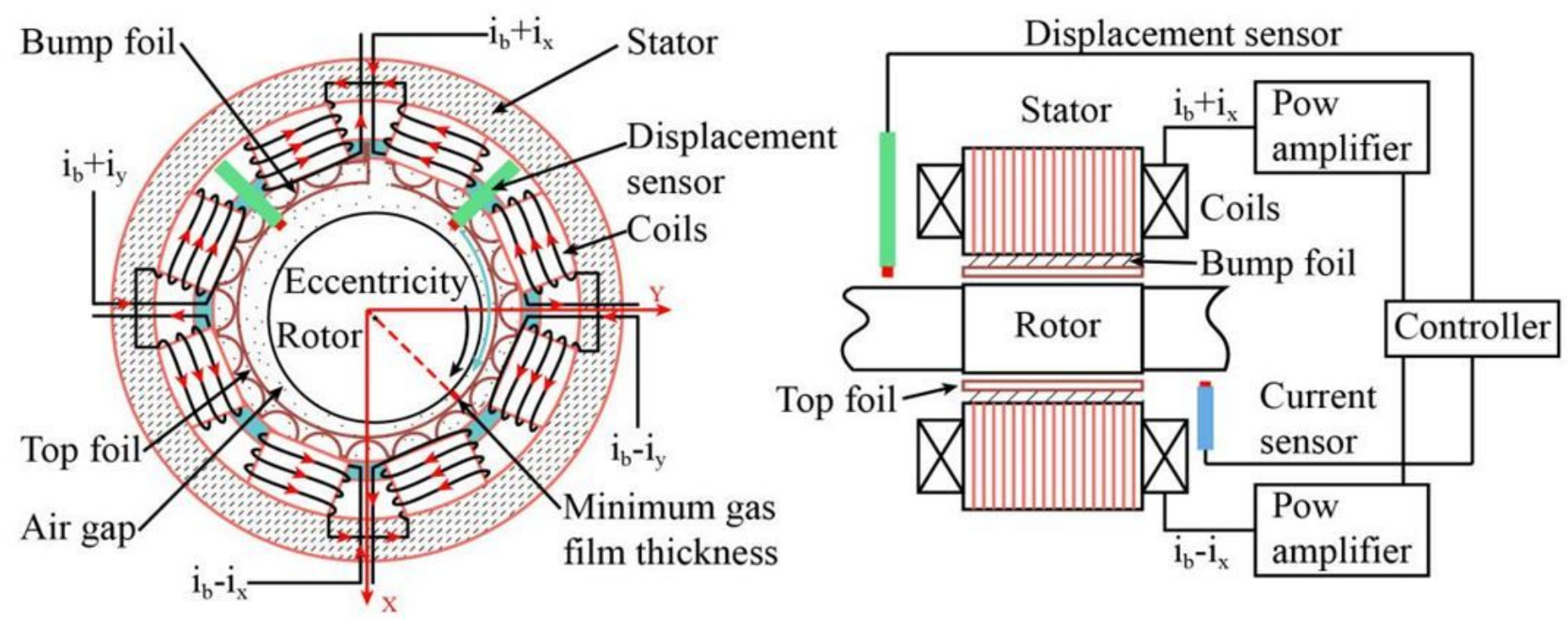

Figure 8 
System structure schematic diagram of hybrid foil magnetic bearings

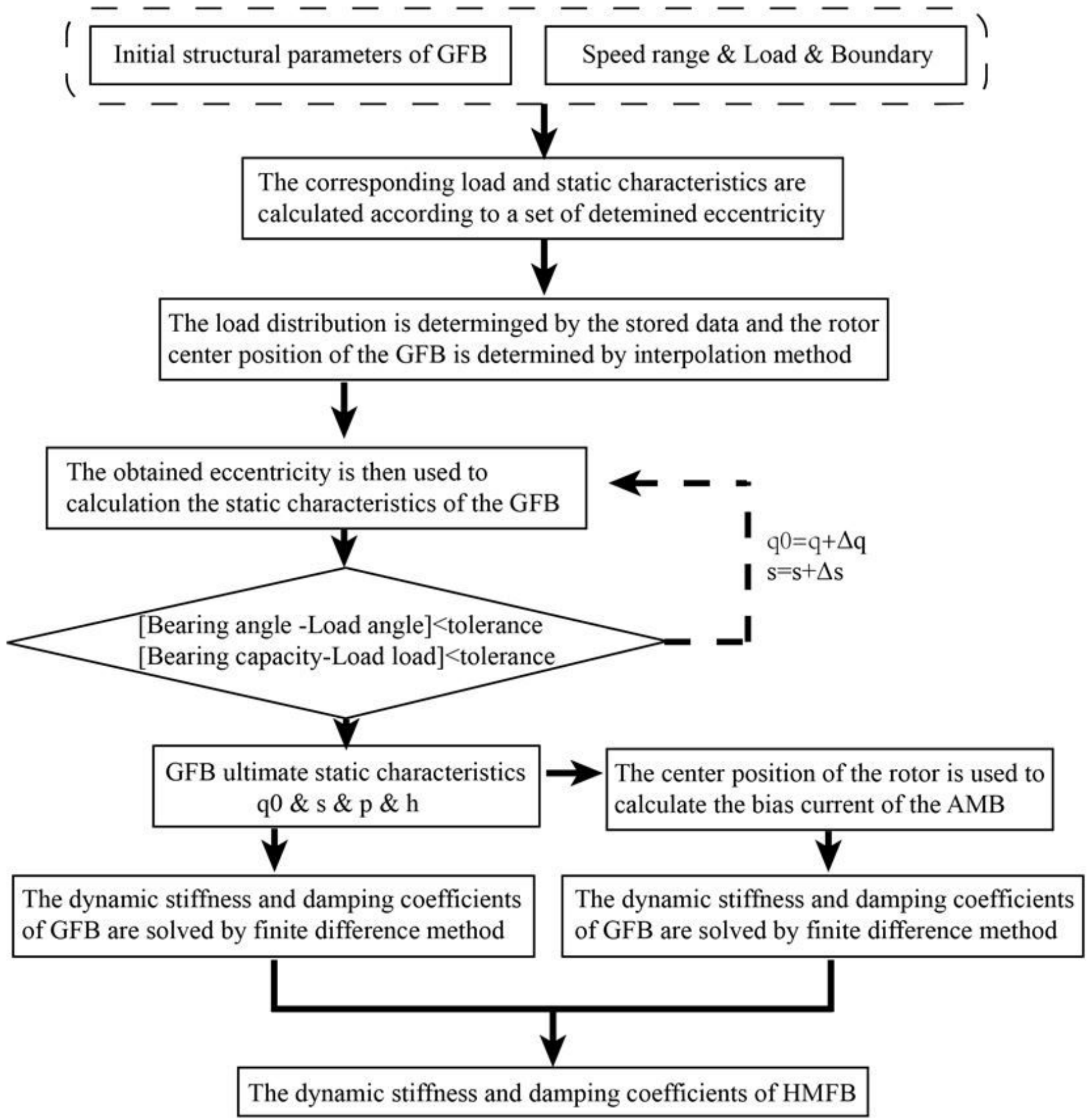

Figure 9

Flowchart for calculating static and dynamic parameters of HFMBs 


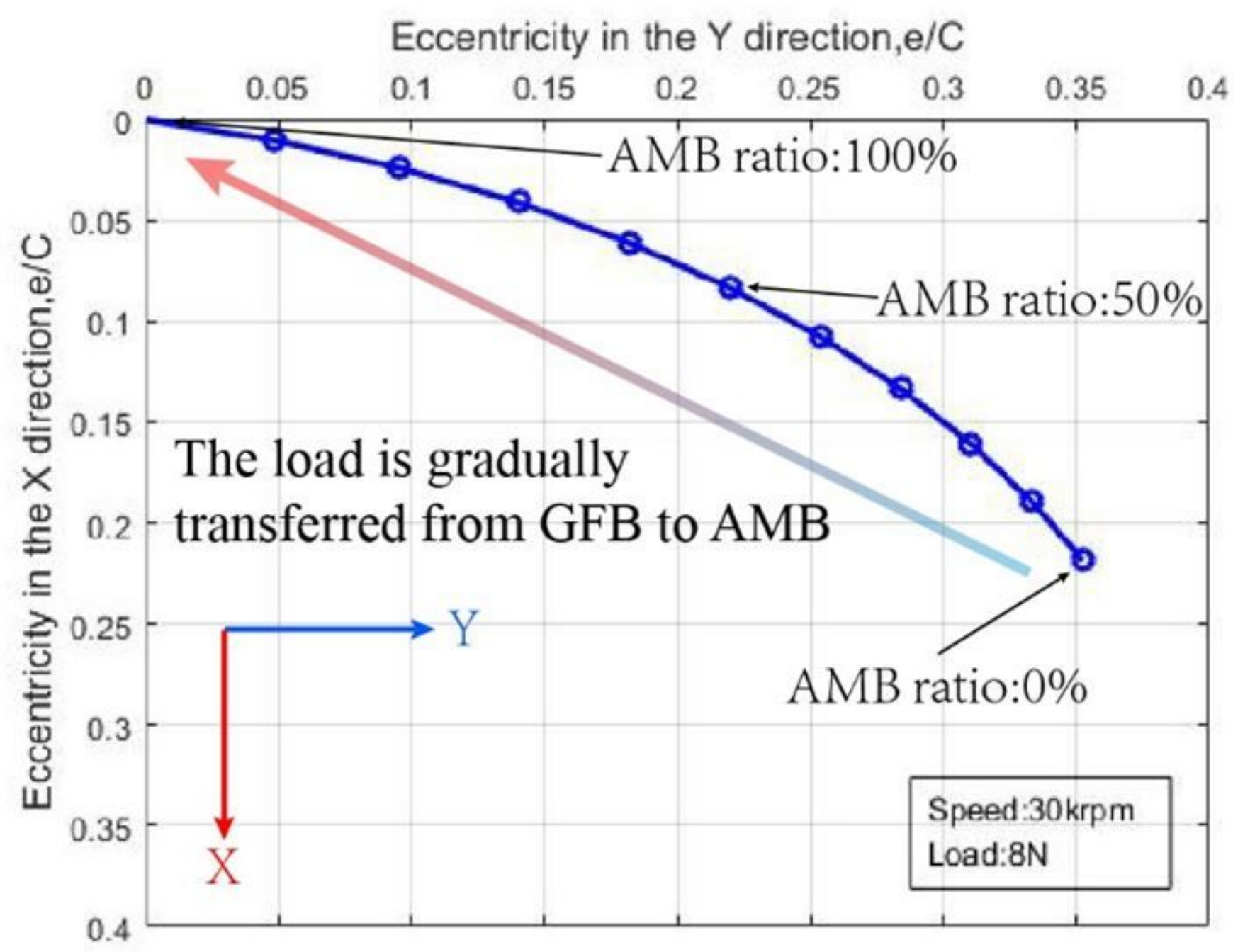

Figure 10

Eccentricity versus different sharing ratio for HFMBs ( rotational speed:30kprm, total load:8N ) 

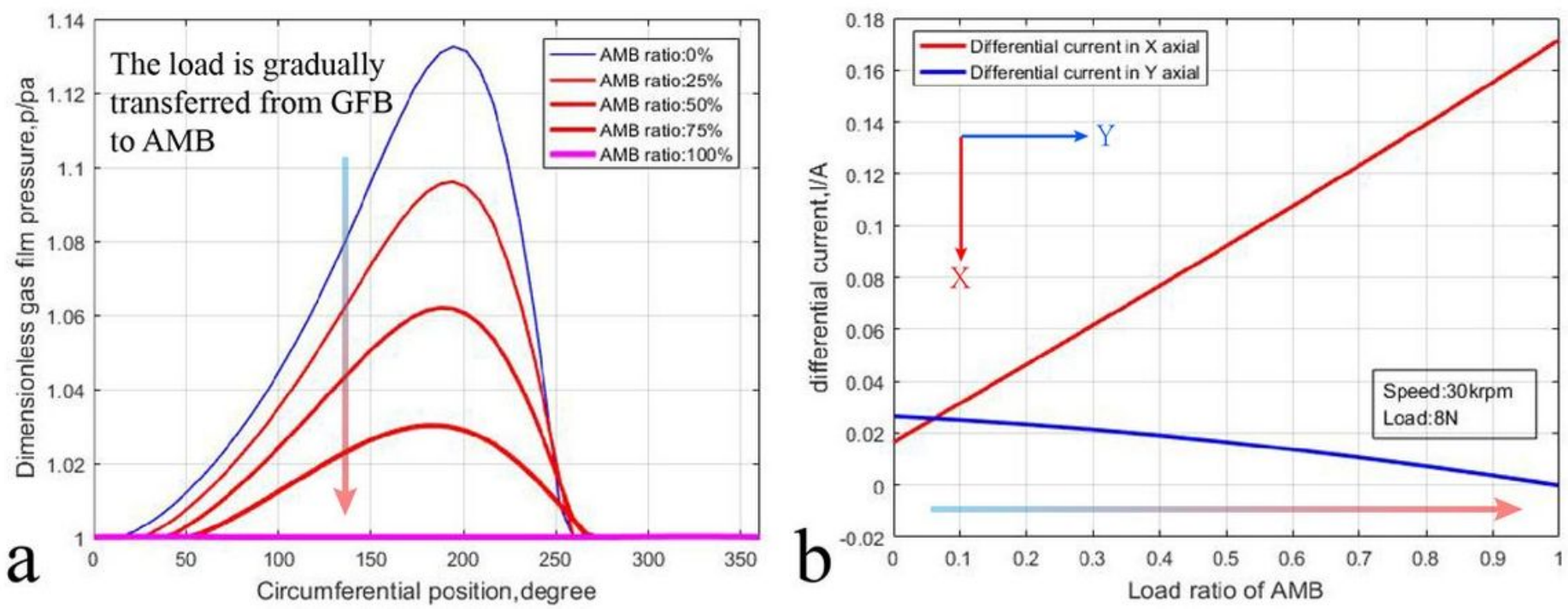

\section{Figure 11}

Air film pressure along the circumferential direction versus AMBs load ratio (a), differential current along $\mathrm{X} / \mathrm{Y}$ direction versus AMBs load ratio (b)囚rotational speed:30kprm, total load:8N】
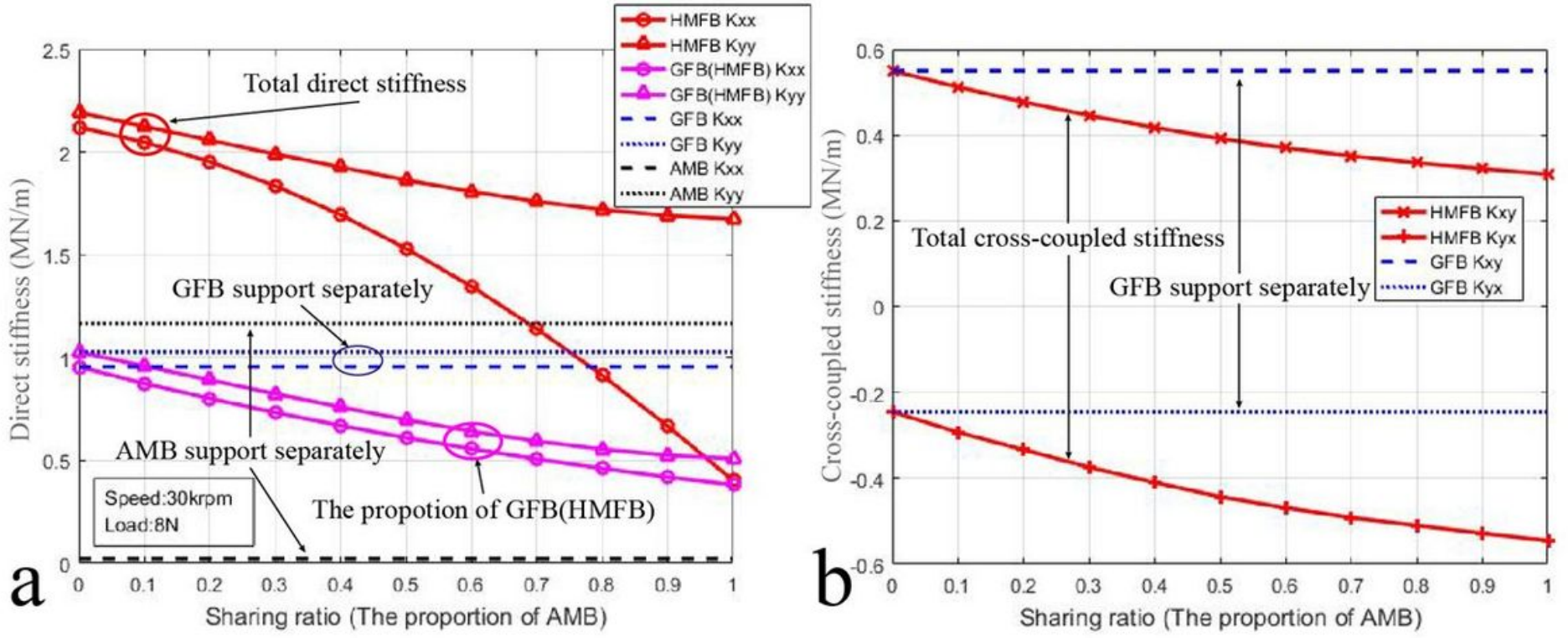

\section{Figure 12}

Dynamic direct stiffness (a) and dynamic cross-coupled stiffness (b) of HFMBs versus AMBs load ratio \rotational speed:30kprm, total load:8N区 


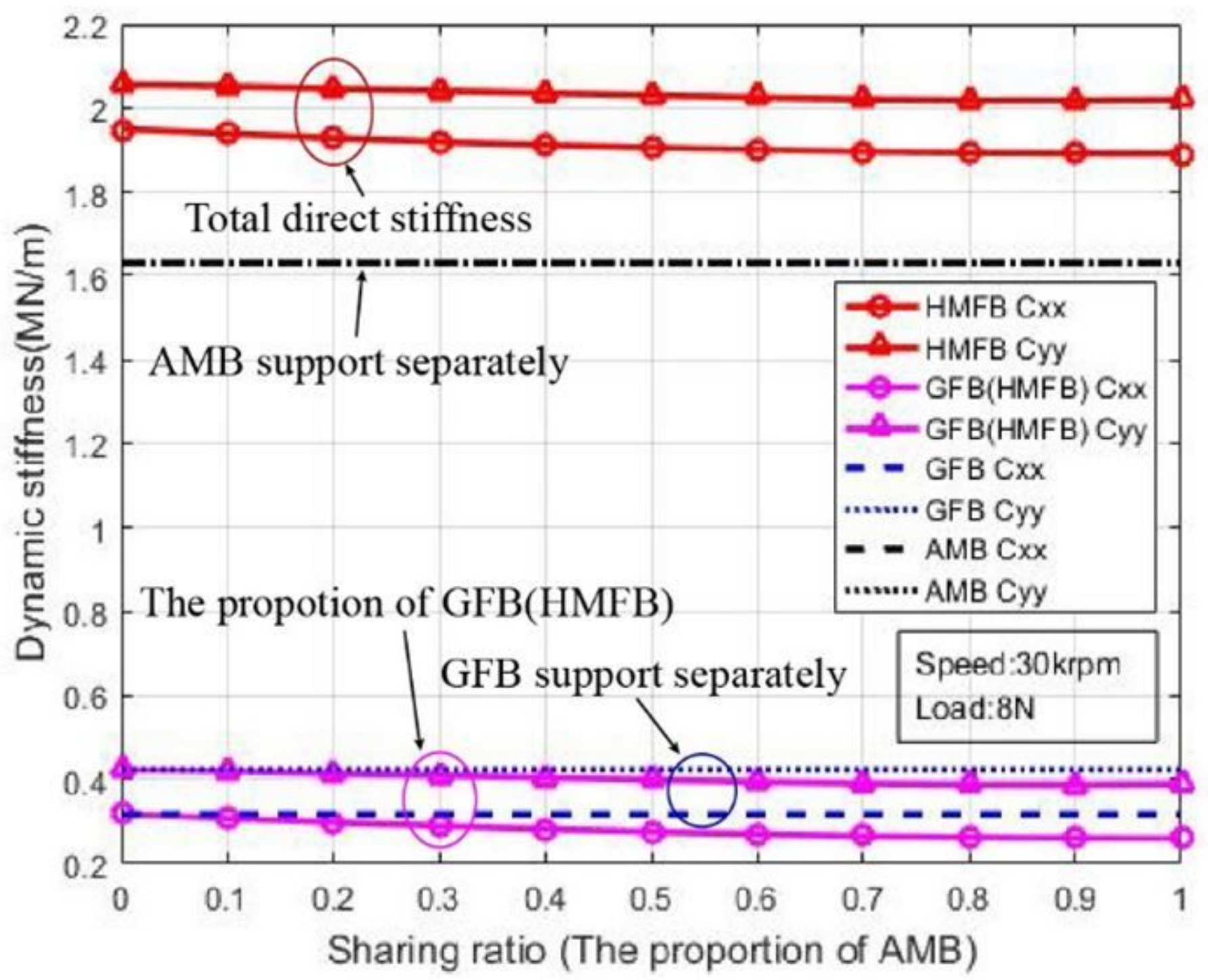

Figure 13

Dynamic direct damping of HFMBs varies with AMBs load ratio (rotational speed: $30 \mathrm{kprm}$, total load: $8 \mathrm{~N} \mathbb{}$ 

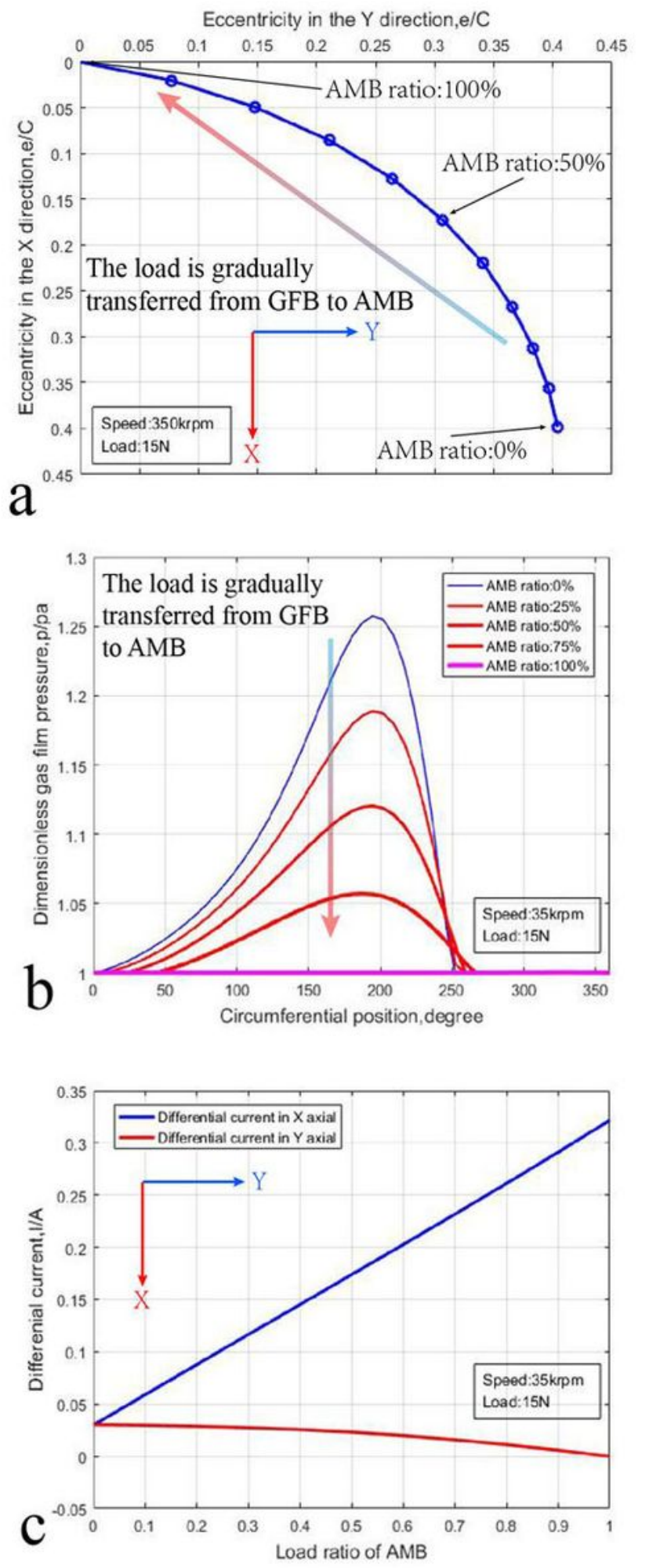

\section{Figure 14}

Variation trend of rotor center (a), air circumferential film pressure (b), and differential current in $X / Y$ directions versus AMBs load ratio (c) (rotational speed:35kprm, total load:15N囚 

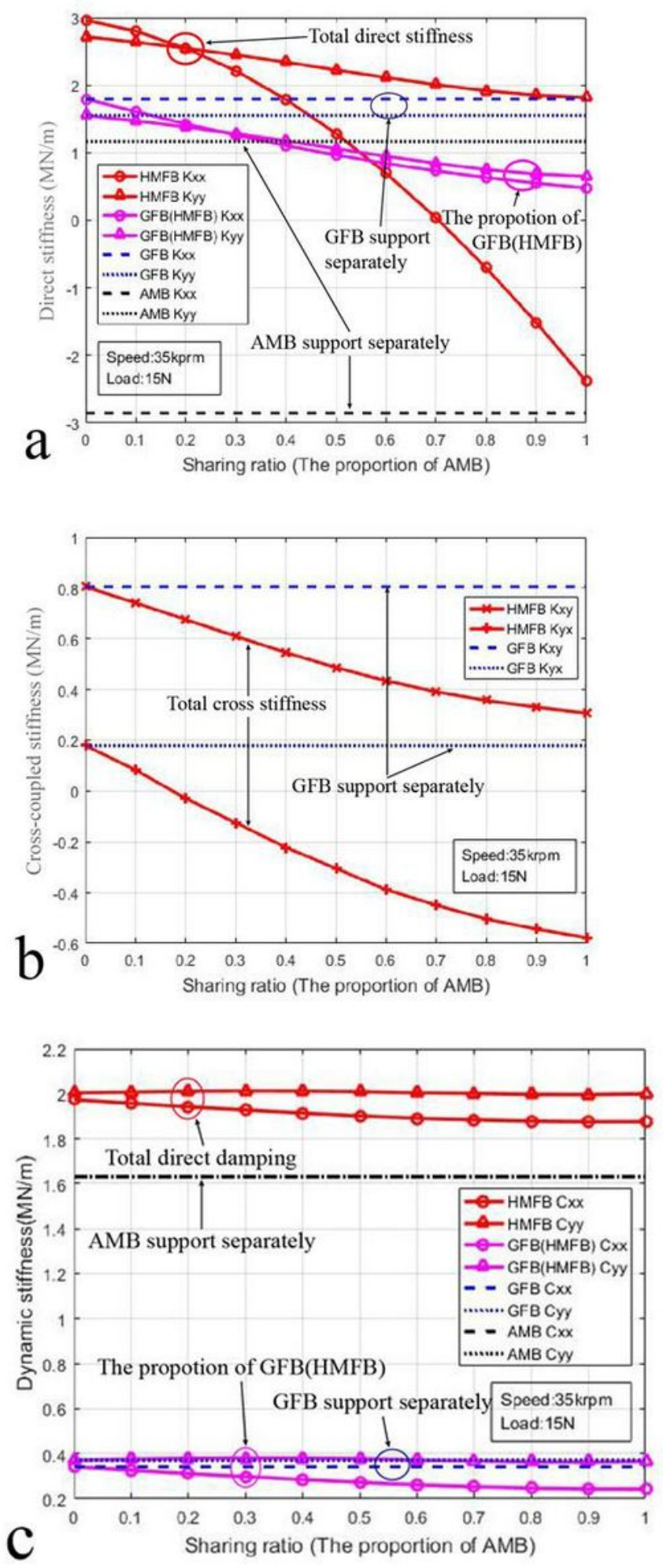

\section{Figure 15}

Dynamic direct stiffness (a), dynamic cross-coupled stiffness (b), dynamic direct damping (c) of HFMBs versus AMBs load ratio (rotational speed:35kprm, total load: $15 \mathrm{~N} \mathbb{}$ 

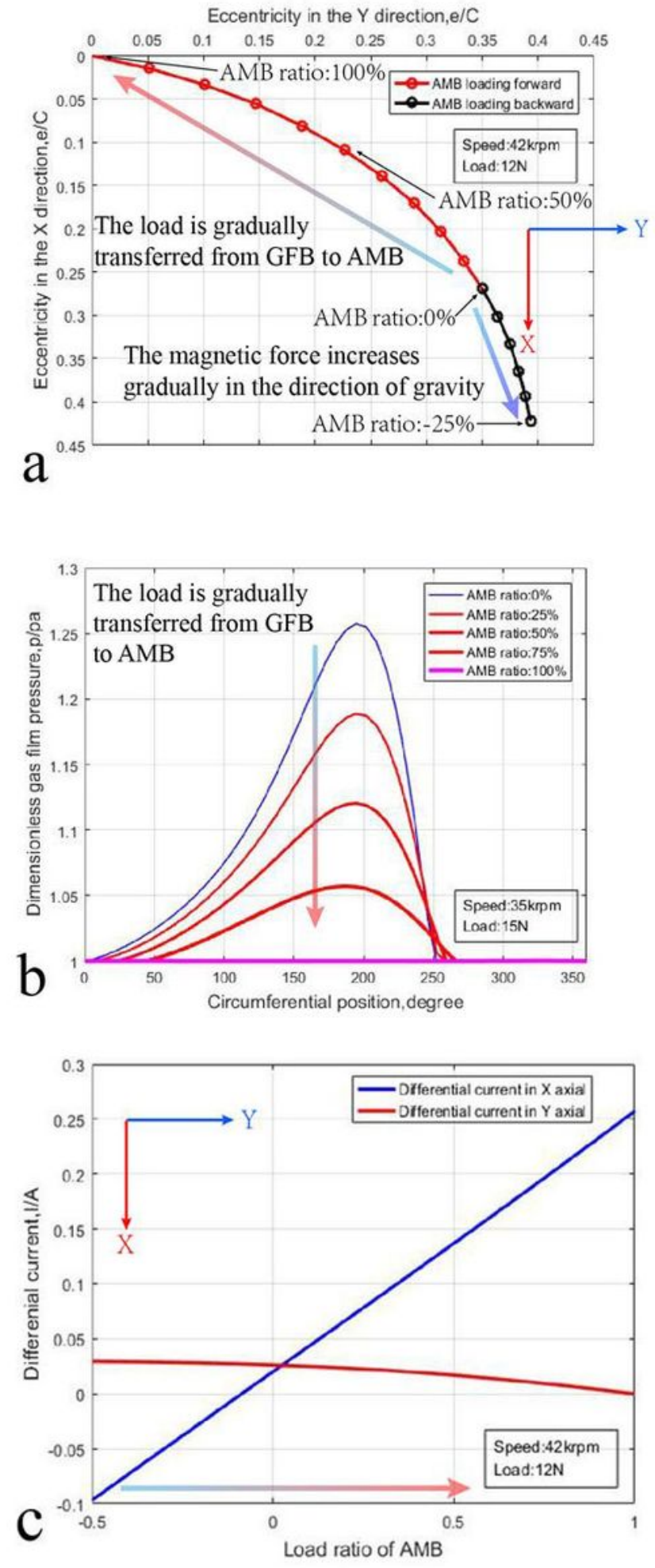

Figure 16

Eccentricity (a), air circumferential film pressure (b), and differential current in $X / Y$ directions versus AMBs load ratio (c), (rotational speed:42kprm, total load:12N囚 

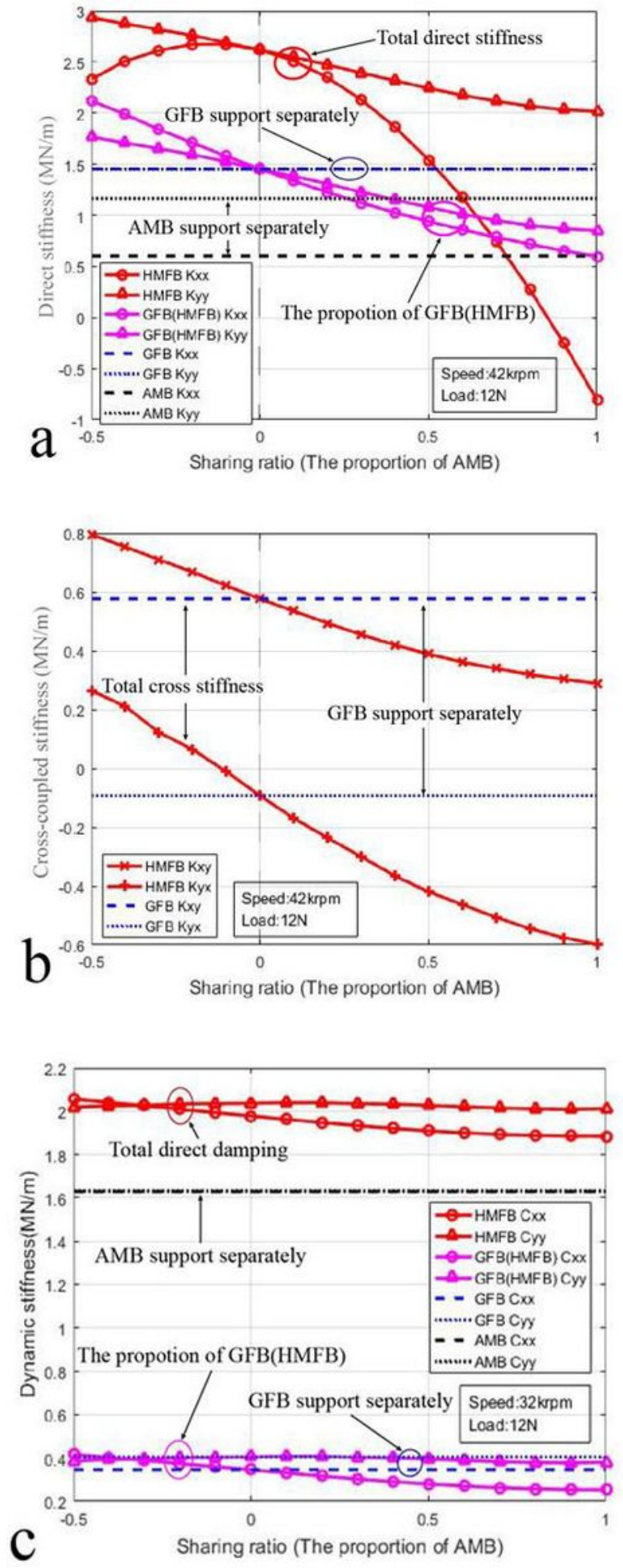

\section{Figure 17}

Dynamic direct stiffness (a), dynamic cross stiffness (b), dynamic direct damping (c) of HFMBs varies with AMBs load ratio (rotational speed:42kprm, total load: $12 \mathrm{~N} \mathbb{}$ 